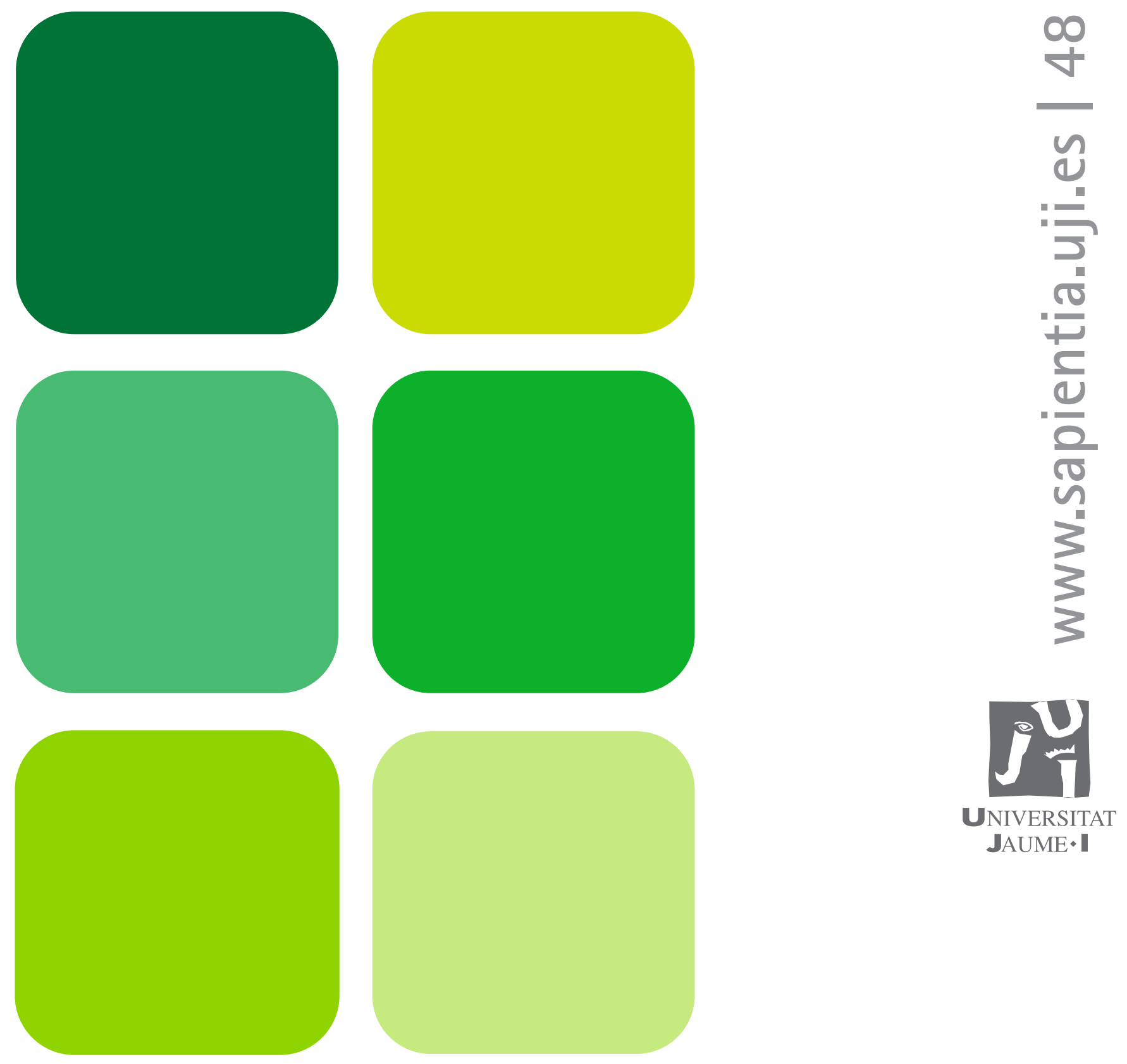

\title{
Gestión integral
}

Teresa Gallego Navarro 


\title{
Gestión integral
}

\author{
Teresa Gallego Navarro
}

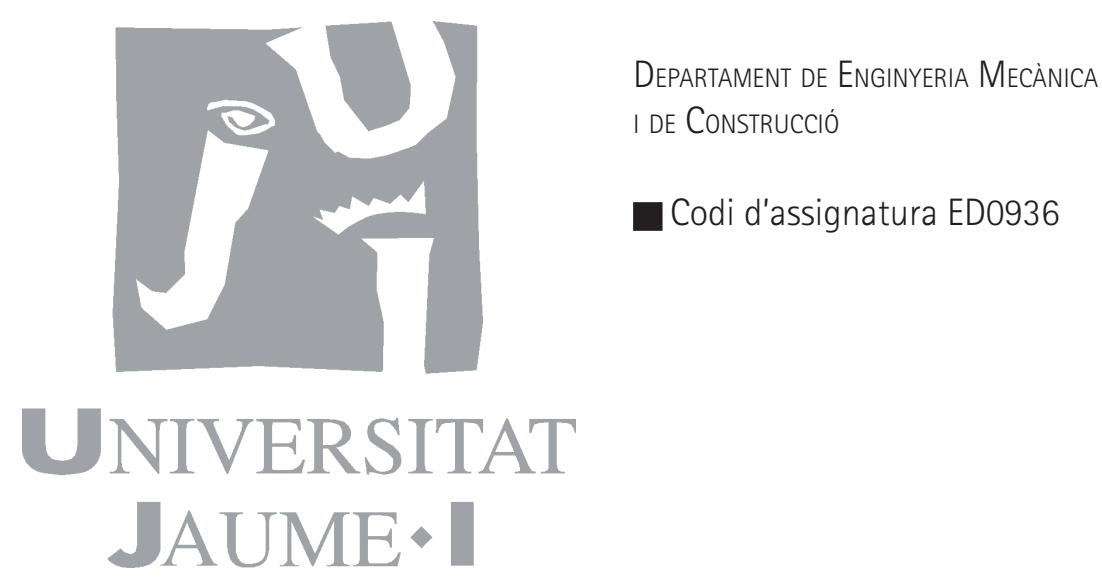


Edita: Publicacions de la Universitat Jaume I. Servei de Comunicació i Publicacions Campus del Riu Sec. Edifici Rectorat i Serveis Centrals. 12071 Castelló de la Plana http://www.tenda.uji.es e-mail: publicacions@uji.es

Col-lecció Sapientia, 48

www.sapientia.uji.es

Primera edició, 2013

ISBN: 978-84-693-9776-3

11 Publicacions de la Universitat Jaume I és una editorial membre de l'UNE, cosa que en garanteix la difusió de les obres en els àmbits nacional i inter-

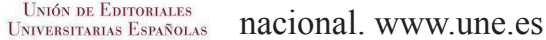

\section{(c) (i) (2)}

Reconeixement-CompartirIgual

\section{BY-SA}

Aquest text està subjecte a una llicència Reconeixement-CompartirIgual de Creative Commons, que permet copiar, distribuir i comunicar públicament l'obra sempre que s'especifique l'autor i el nom de la publicació fins i tot amb objectius comercials i també permet crear obres derivades, sempre que siguen distribuïdes amb aquesta mateixa llicència.

http://creativecommons.org/licenses/by-sa/3.0/legalcode 


\section{ÍNDEX}

Tema 1

Introducción a los sistemas de gestión integrados . . . . . . . . . 5

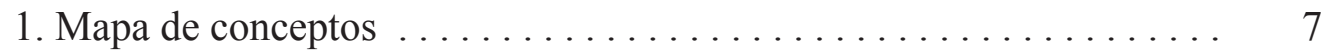

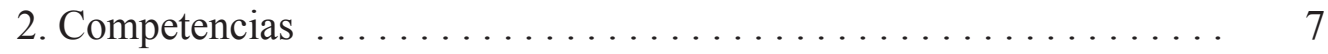

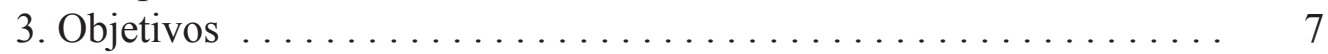

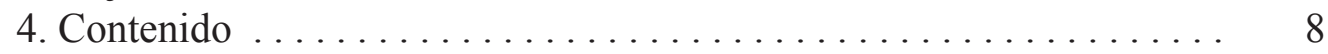

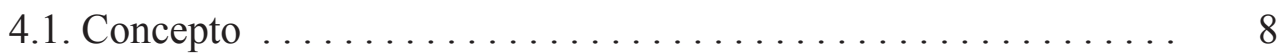

4.2. Ventajas e inconvenientes de la implantación de un sistema

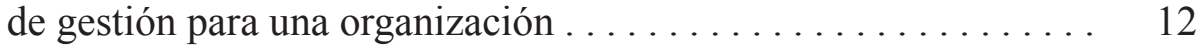

4.3. Alcance de la gestión en una organización del sector

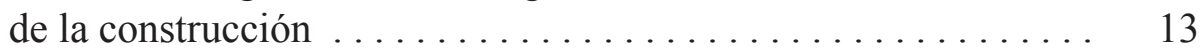

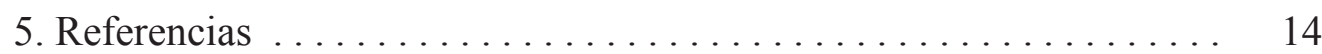

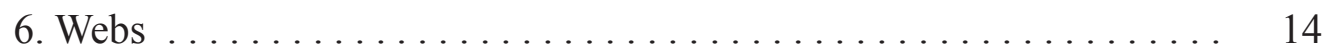

Tema 2

Modelos normalizados de gestión $\ldots \ldots \ldots \ldots \ldots \ldots \ldots \ldots \ldots \ldots \ldots$

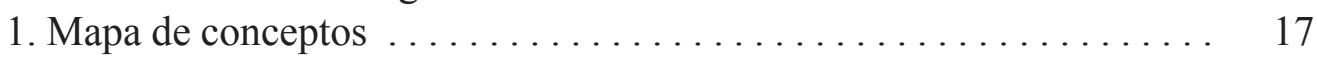

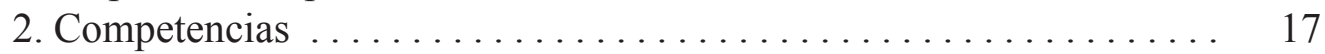

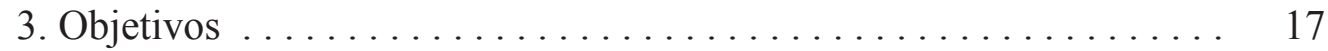

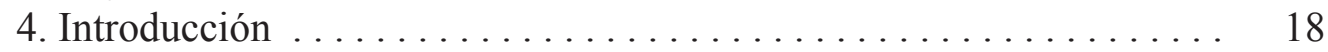

5. Contenido ............................... 19

5.1. Modelos para la gestión de la calidad . . . . . . . . . . . . 19

5.2. Modelos para la gestión medioambiental de la organización .... 24

5.3. Modelos para la gestión de la prevención de los riesgos laborales de la organización ............... 31

5.4. Modelos para la gestión de la innovación de la organización . . . 33

5.5. Modelos para la gestión del conocimiento de la organización .... 35

5.6. Modelos para la gestión de la responsabilidad social

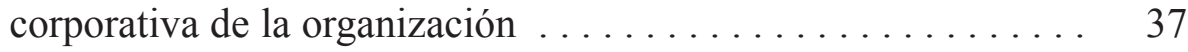

6. Referencias ........................... 41

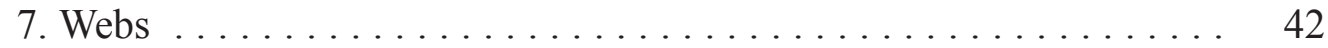

Tema 3

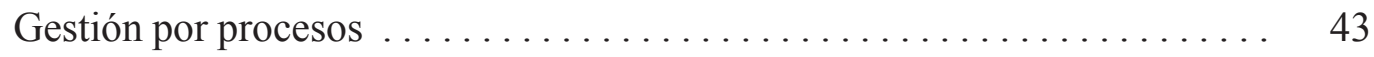

1. Mapa conceptual ......................... 45

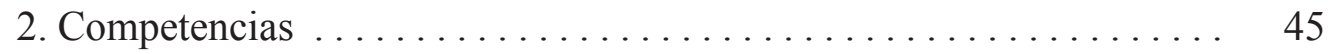

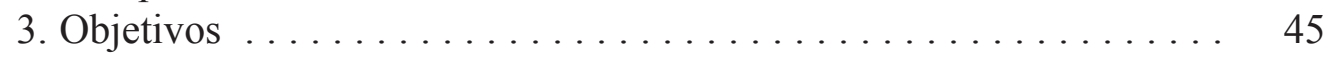




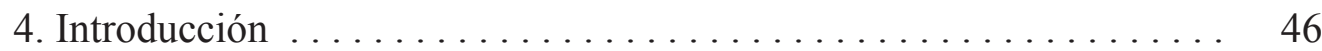

5. Gestión por procesos según las normas iso 9001:2008 . . . . . . . . 47

6. Gestión por procesos según el modelo EFQM $2010 \ldots \ldots \ldots \ldots \ldots \ldots 49$

7. La definición de un sistema de gestión basado en procesos

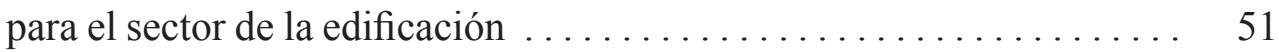

7.1. Determinación o identificación de los procesos necesarios en

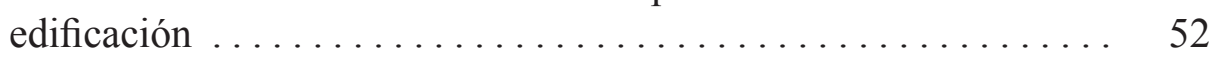

7.2. Determinar la secuencia o interacción entre los procesos

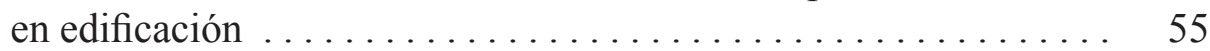

7.3. Seguimiento de los procesos $\ldots \ldots \ldots \ldots \ldots \ldots \ldots \ldots$

8. Referencias .......................... 58

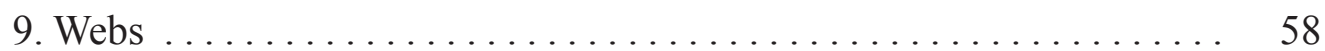

Tema 4

Gestión de los documentos . . . . . . . . . . . . . . . . . . . . . . 59

1. Mapa de conceptos .......................... 61

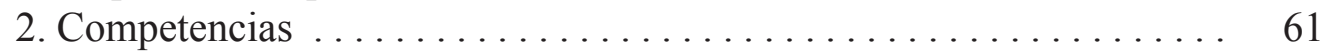

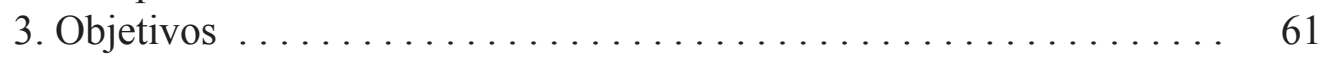

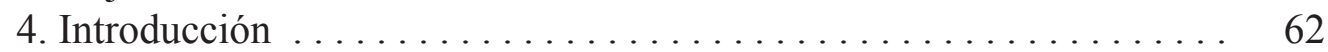

5. Contenido ............................. 63

5.1. Referencia a norma .................. 63

5.2. Referencia a la legislación vigente para el sector de la edificación ......................... 64

5.3. Identificación y contenido de los documentos del sistema

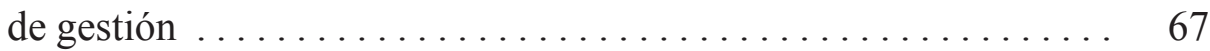

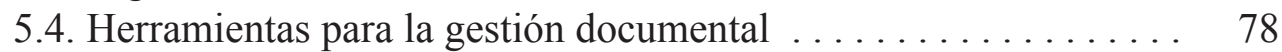

6. Referencias .............................. 78

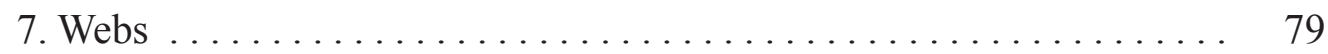




\section{TEMA 1}

\section{Introducción a los sistemas de gestión integrados}

1. Mapa de conceptos

2. Competencias

3. Objetivos

4. Contenido

4.1. Concepto

4.2. Ventajas e inconvenientes de la implantación de un sistema de gestión para una organización

4.3. Alcance de la gestión en una organización del sector de la construcción

5. Referencias

6. Webs 


\section{Mapa de conceptos}

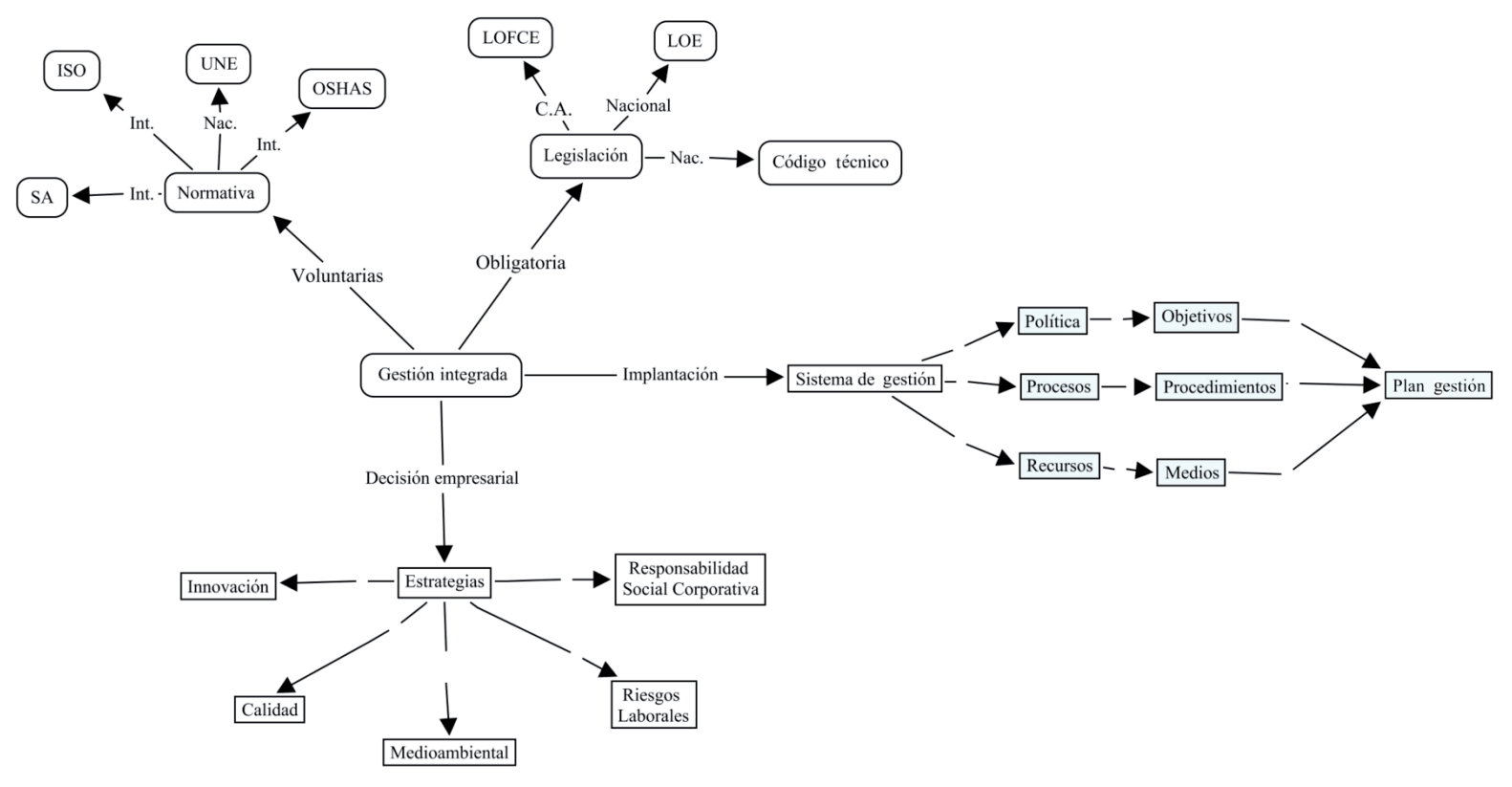

\section{Competencias}

ME18. ${ }^{1}$ Conocimiento del derecho de la construcción de las relaciones contractuales que se produzcan en las diferentes fases del proceso de edificación, así como de la legislación, reglamentación y normativas específicas de la prevención y coordinación en materia de seguridad y salud laboral en la edificación.

OP18. ${ }^{2}$ Gestionar las nuevas tecnologías y participar en los procesos de gestión de la calidad en la edificación; realizar análisis, evaluación y certificaciones de eficiencia energética así como estudios de sostenibilidad en los edificios.

\section{Objetivos}

En este tema se pretende dar a conocer qué es la gestión integrada en una empresa del sector de la construcción. Se informa del significado del propio concepto y se da a conocer las necesidades de la misma para una organización. Así como se informa

1. En este tema la competencia a desarrollar tan solo abarca el conocimiento de la legislación y normativa referente a la organización empresarial para implantar gestión integral.

2. Respecto a esta competencia, en este tema se pretende que el alumno aprenda la gestión integrada de los procesos. 
de las normas de referencia nacional e internacionales independientes para conseguir distintas estrategias empresariales, las cuales pueden ayudar a definir un plan de gestión integrado.

\section{Contenido}

\subsection{Concepto}

Según el Diccionario de la Real Academia Española, se entiende por Gestión es «la acción y efecto de gestionar o administrar».

Según la norma [1] Iso 9000:2005 Sistemas de gestión de la calidad, fundamentos y vocabulario, se define Gestión como «las actividades coordinadas para dirigir y controlar una organización». Sistema de Gestión como «conjunto de elementos mutuamente relacionados o que interactúan para establecer la política y los objetivos y para lograr dichos objetivos». Nota: un sistema de gestión de una organización podría incluir diferentes sistemas de gestión, tales como un sistema de gestión de la calidad, un sistema de gestión financiera o un sistema de gestión ambiental. Como primera aproximación al concepto de Gestión Integral o Sistema de gestión único, la norma ISO 9000:2005, en su apartado que hace referencia a «los Sistemas de gestión de la calidad y otros sistemas de gestión» define que es aquella parte del sistema de gestión de la organización enfocada en el logro de resultados, en relación con los objetivos de la calidad, para satisfacer las necesidades, expectativas y requisitos de las partes interesadas, según corresponda. Los objetivos de la calidad complementan otros objetivos de la organización, tales como aquellos relacionados con el crecimiento, los recursos financieros, la rentabilidad, el medio ambiente y la seguridad y la salud ocupacional. Las diferentes partes del sistema de gestión de una organización pueden integrarse conjuntamente con el sistema de gestión de la calidad, dentro de un sistema de gestión único, utilizando elementos comunes. Esto puede facilitar la planificación, la asignación de recursos, el establecimiento de objetivos complementarios y la evaluación de la eficacia global de la organización. El sistema de gestión de la organización puede evaluarse comparándolo con los requisitos del sistema de gestión de la organización. El sistema de gestión puede asimismo auditarse contra los requisitos de Normas Internacionales tales como ISO 9001 e ISO 14001. Estas auditorías del sistema de gestión pueden llevarse a cabo de forma separada o conjunta.

Si tomamos como referencia la legislación de obligado cumplimiento para el sector de la edificación en España, y concretamente en la Comunidad Valenciana, esta hace referencia a la necesidad de gestionar las empresas en:

Según [1] Ley 3/2004, de 30 de junio, de Ordenación y Fomento de la Calidad de la Edificación de la Comunidad Valenciana (LOFCE), se entiende por calidad de un 
edificio, el conjunto de características que reúne y prestaciones que proporciona el referido edificio, para satisfacer las necesidades y expectativas de los usuarios y de otras partes interesadas que intervienen en el proceso de edificación o se ven afectadas por él.

Por su parte, la norma [2] Iso 8402:1994 define calidad como el «conjunto de propiedades y características de un producto o servicio que le confieren su aptitud para satisfacer unas necesidades expresas o implícitas».

Otros conceptos afines surgidos de este proceso evolutivo son:

Calidad total: término que sitúa como primer objetivo de la gestión empresarial la calidad del producto o servicio ofrecido y la satisfacción del cliente a través de la mejora continua.

Mejora continua: se denomina así a la mejora sistemática y constante de los procesos mediante la implementación de la metodología y herramientas adecuadas / desarrollar actividades con el fin de incrementar la habilidad y cumplir los requisitos.

Excelencia: se define así el conjunto de prácticas sobresalientes en la gestión de una organización y el logro de resultados basados en conceptos fundamentales que incluyen la orientación hacia los resultados, orientación al cliente, liderazgo, implicación de las personas, mejora continua e innovación, alianzas mutuamente beneficiosas, responsabilidad social.

Por tanto, podríamos concluir que el concepto tan amplio del término calidad ha sido motivado por la propia evolución que han sufrido las técnicas utilizadas para detectar la calidad en el seno de una organización empresarial, principalmente por dos motivos: uno obligatorio para cumplir con la legislación vigente, cada vez más exigente, y otro voluntario para conseguir mejoras competitivas.

Si realizamos un estudio retrospectivo de la evolución histórica empresarial vemos que todo se inició cuando a principios de siglo. Con una competencia industrial que era cada vez mayor, el sector industrial se dio cuenta de la necesidad de no sacar al mercado productos o piezas con defectos. Se inició por tanto la costumbre de realizar tareas de inspección durante la producción, por lo que analizaban o se ensayaban los materiales y productos para determinar si eran aptos o no para su venta.

Las inspecciones, en un principio, evitaron problemas de reclamaciones. Pronto se dieron cuenta de que tan solo les aseguraba que no aparecerían productos no defectuosos, si se analizaban todos. Esto supone un elevado coste para la empresa, reduciendo por tanto la eficacia del método.

Pronto se realizaron estudios que comprobaron que si aplicaban técnicas de control estadístico, los resultados mejoraban la eficacia del control, porque se pudo comprobar que el margen de error que podía suponer el hacer un control estadístico 
en contraste a realizar un control al $100 \%$ era tan bajo que no compensaba el exceso de coste que ello suponía. Por lo que a partir de entonces se realizaban inspecciones planificadas, tomando varias muestras representativas de los lotes identificados.

Posteriormente, la industria se vio presionada por la necesidad de reducir aun más los costes, por lo que se estableció con el nombre de calidad concertada u otros equivalentes, por el que se eliminaron las verificaciones de recepción. Se basaba en un precio acordado desde contrato que debía de corresponder a un producto de calidad o, como se conoce ahora, cumplir con unas especificaciones técnicas. De esta forma era el propio proveedor el que tenía que asegurar la calidad previamente.

Con este avance las empresas empezaron a definir sus propios procedimientos de trabajo y normas internas que obligaban de manera contractual a controlar los sistemas productivos del proveedor, para así asegurarse de su capacidad y su responsabilidad. A este conjunto de criterios y normas que cada una de las empresas estableció, se le dio el nombre genérico de aseguramiento de la calidad. Esta tendencia propició que se generaran normas internacionales, establecidas por un organismo internaciona: International Organization for Standardization (ISO), que estableció un referente para alcanzar el aseguramiento de la calidad de la organización de la empresa, diferente a asegurar la calidad de los productos.

Siguiendo en este proceso evolutivo la empresa pasó a considerar la calidad como una estrategia global, de manera que se pretende involucrar a toda la organización con la gestión de la calidad. En un principio esta gestión se regía con un único factor estratégico: la calidad, pero cada día más se añaden otros factores estratégicos como podría ser la prevención o respeto al medio ambiente, la innovación, la responsabilidad social corporativa, de manera que la propia organización de la empresa se basa en una gestión integral, ofreciendo a sus clientes productos/servicios con valor añadido.

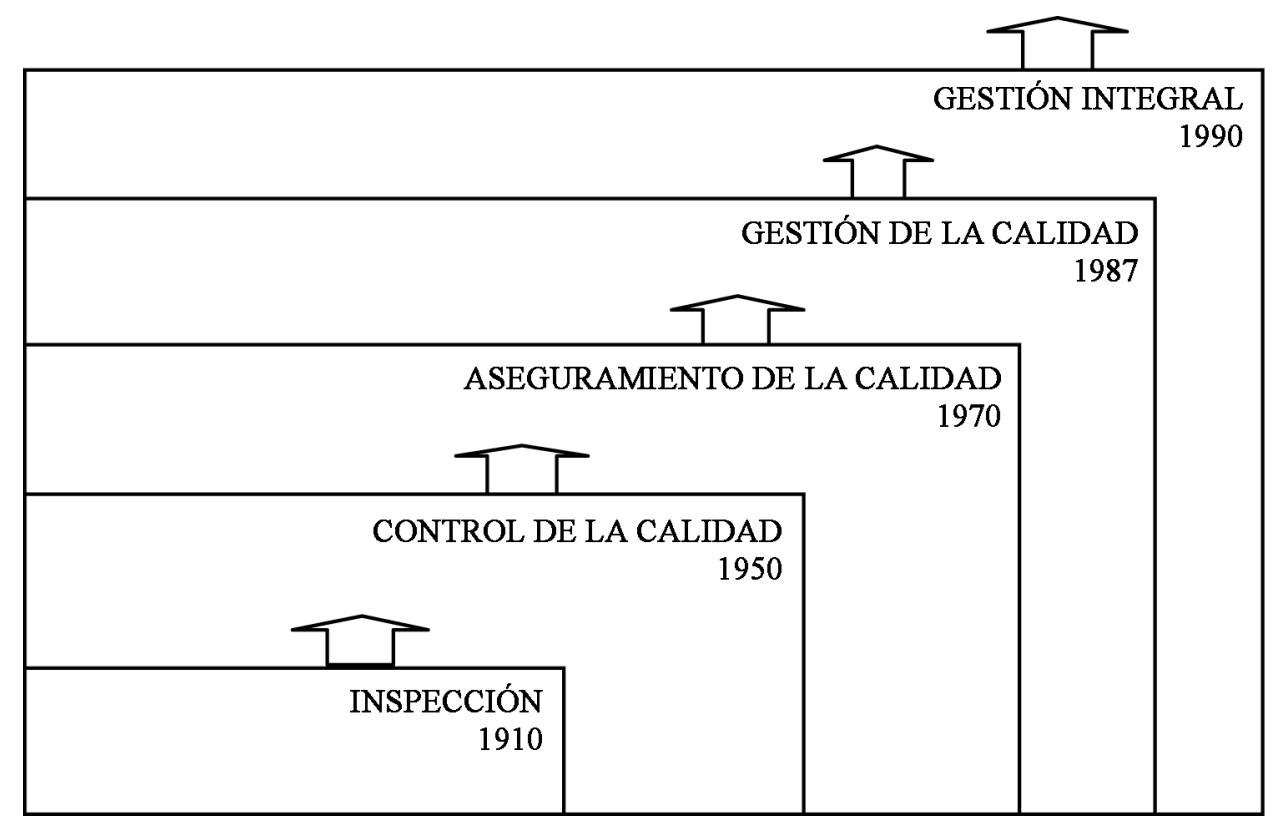

Figura 1: Evolución del concepto de la calidad industrial 
Como se puede comprobar en el gráfico de la evolución (figura 1), cada avance implicaba necesariamente la aplicación de la fase anterior; por tanto, realizar el control de la calidad de una obra de edificación significa planificar el número de ensayos o inspecciones necesarios según cantidad de material a utilizar o según superficie construida.

Según la evolución histórica de la calidad y como vemos representada en el esquema de la figura 1, los distintos conceptos que la calidad no han ido adoptando conceptos opuestos o incluso eliminatorios, sino que han evolucionado, unas completando a las otras, siempre siguiendo el interés por mejorar. Por ello el control de calidad nos lleva al aseguramiento de la calidad, esta a la gestión de la calidad y se tiende hacia la gestión integral donde se reúnen todas las estrategias que se pretenden conseguir en una organización industrial, y hacia la gestión de la innovación, cuyo objetivo es predecir, adelantarse a las necesidades de nuestros clientes.

En España por AENOR, con el código UNE EN-ISO las normas de referencia para mejorar la gestión de la empresa se pueden agrupar según su estrategia en:

- Calidad, la norma Iso 9001:2008, norma que adaptada por España es traducida en UNE EN-ISO 9001:2008.

- Medioambiental, la norma UNE EN-ISO 14001:2004.

- Prevención de riesgos, la norma OHSAS 18001:2007.

- Responsabilidad social corporativa, sa 8000:2008.

- Gestión de la innovación tecnológica, UNE 166002:2006.

Teniendo en cuenta que la primera norma que fue internacionalmente aceptada e implantada fue la norma Iso 9001 para la gestión de la calidad que ha ido evolucionando desde su primera edición en 1994 hasta la última publicada en 2008, el resto han seguido los mismos principios la mejora continua, basado en el cículo de Deming: Planifica, Desarrolla, Controla y Mejora y la gestión por procesos.

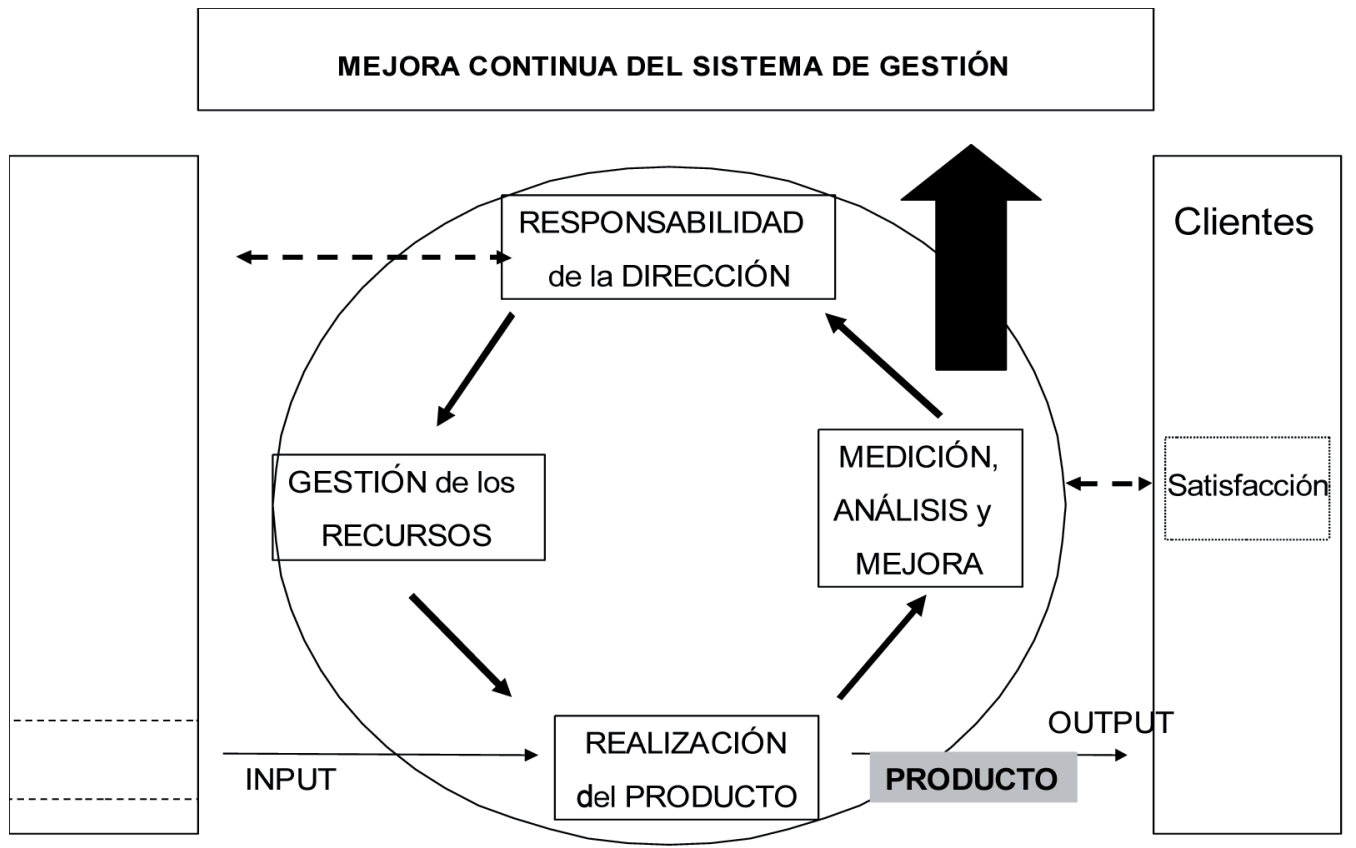

Figura 2: Modelo de un sistema de gestión de la calidad basado en procesos según ISO 9001 


\subsection{Ventajas e inconvenientes de la implantación de un sistema de gestión para una organización}

Muchas son las preguntas que los directivos de una empresa se hacen previo a la decisión de implantar sistemas de gestión normalizados en su empresa:

¿Qué modelo de gestión implantar?

¿Depende del tipo de organización?

¿Es de interés en nuestro mercado?

¿Ofrecen realmente ventajas competitivas?

¿El coste es muy elevado?

Si analizamos estudios de opinión recientes realizados entre pequeñas y medianas empresas constructoras dedicadas a la ejecución de obras de edificación de la región de Murcia [4], que por el momento solo han implantado gestión de la calidad según ISO 9001, podemos decir; que ellas mismas consideran como ventaja:

- Que es una mejora competitiva.

- Que les abre a mercados nacionales y a convocatorias de ofertas públicas.

- Que mejoran su imagen de empresa.

- Que mejora la gestión general de la empresa: la organización, la planificación y orden en los trabajos.

- La optimización y control de los procesos.

- Sistema de documentación útil y controlado.

- Mayor satisfacción del cliente.

- Disponer de herramientas de medida para identificar oportunidades de mejora.

- Conocer los puntos débiles de la empresa.

- Mejora continua.

Respecto a los resultados de la obra:

- Mejora en la productividad.

- Mejor uso de recursos y medios.

- Reducción en los defectos de la obra.

- Mejora del producto final.

- Menor número de reclamaciones del cliente.

Pero no nos podemos olvidar de los inconvenientes, que aunque son pocos en número no significa que sean pocos en importancia:

- El tiempo empleado. Significa dedicarle bastante tiempo y trabajo. Esta dedicación es especialmente difícil de conseguir incluso por parte de los directivos, 
a no ser que estos estén comprometidos y tengan una visión clara de la utilidad estratégica, que al principio no es muy visible.

- Se producirá el fenómeno típico de resistencia al cambio. Si esta resistencia ya hacia todo lo que supone novedad es algo congénito a la naturaleza humana, en este caso en particular puede ser particularmente grave, dado que esta filosofía va a modificar completamente muchas teorías comúnmente implantadas y los esquemas culturales de la mayoría de las empresas que conocemos.

- La excesiva documentación y su utilidad. Mucha es la documentación que hay que generar para definir el sistema, pero aún más es la documentación que hay que gestionar para demostrar la implantación del sistema, por lo que para empresas poco habituadas al control documental, puede ser un escollo infranqueable.

Aún así, hay un aspecto identificado como inconveniente por las empresas pero creo que no lo debemos olvidar: la fuerte inversión económica que en las primeras fases es necesario desembolsar para la instauración de un sistema de gestión, como es la inversión en subcontratación de consultorías, recursos humanos y técnicos, así como, la certificación de empresa.

Nadie está diciendo que implantar un sistema de gestión vaya a ser fácil, de todos es sabido que los caminos de rosas están cuajados de espinas, de manera que debemos ser conscientes de todos los inconvenientes desde el principio, sobre todo en los comienzos que es cuando aparecen el mayor número de problemas.

Por tanto, conociendo ya de antemano las principales dificultades y objeciones con las que posiblemente tropezaremos se recomienda:

- Planteamiento correcto desde el inicio.

- Convencimiento de la dirección.

- Nombrar una persona encargada únicamente de esta función.

- Redactar documentos útiles, sencillos y fácilmente entendibles.

- No generar burocracia.

- Marcarse objetivos claros a corto/medio/largo plazo.

\subsection{Alcance de la gestión en una organización del sector de la construcción}

Las particularidades del sector de la construcción que están relacionadas en el cambio de ubicación del lugar de trabajo, y el cambio personal implicado en cada una de sus obras, hacen en ocasiones difícil a las organizaciones definir un sistema de gestión adaptado a dichas necesidades. Pero la realidad es que gracias a las experiencias de empresas, así como de auditores, se considera que la implantación de un sistema de gestión mejora la organización, no solo de la central, sino de sus obras en particular porque cada una de ellas requiere de una correcta planificación, de su seguimiento y control; así como de su mejora continua y por ello toda obra se rige por su plan de calidad específico. 
Lejos queda ya la posibilidad de limitar el alcance de la implantación del sistema a departamentos o tipos de obras. Tan solo se permite la exclusión del proceso de diseño, si la empresa no desarrolla y no se responsabiliza del diseño final del proyecto.

\section{Referencias}

[1] Norma UNE-EN ISO 9000:2005 Sistemas de gestión de la calidad, fundamentos y vocabulario.

[2] Ley 3/2004, de 30 de junio, de Ordenación y Fomento de la Calidad de la Edificación de la Comunidad Valenciana (LOFCE).

[3] Proyecto final de Master en Gestión de la Edificación 2009: Los beneficios que se obtienen al implantar un sistema de gestión de la calidad en empresas constructoras. González Ponce, Eloísa.

\section{Webs}

Asociación española para la normalización y certificación www.aenor.es International Organization for Standardization www.iso.org/iso/home.htm 


\title{
TEMA 2
}

\section{Modelos normalizados de gestión}

\author{
1. Mapa de conceptos \\ 2. Competencias \\ 3. Objetivos \\ 4. Introducción \\ 5. Contenido
}

5.1. Modelos para la gestión de la calidad de la organización

5.2. Modelos para la gestión medioambiental de la organización

5.3. Modelos para la gestión de la prevención de los riesgos laborales de la organización

5.4. Modelos para la gestión de la innovación de la organización

5.5. Modelos para la gestión del conocimiento de la organización

5.6. Modelos para la gestión de la responsabilidad social corporativa de la organización

6. Referencias

7. Webs 


\section{Mapa de conceptos}

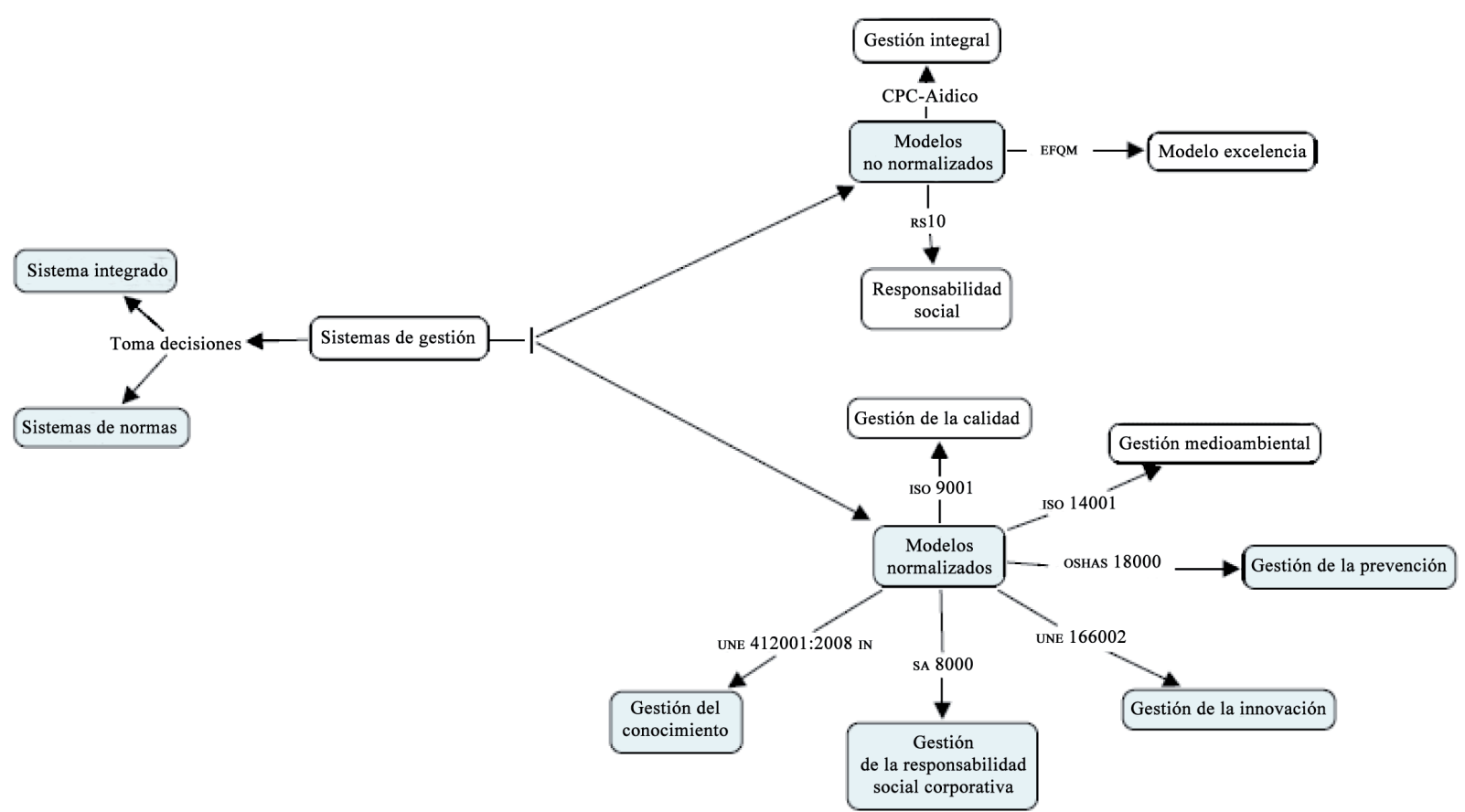

\section{Competencias}

ME18. ${ }^{1}$ Conocimiento del derecho de la construcción de las relaciones contractuales que se produzcan en las diferentes fases del proceso de edificación, así como de la legislación, reglamentación y normativas específicas de la prevención y coordinación en materia de seguridad y salud laboral en la edificación.

OP18. ${ }^{2}$ Gestionar las nuevas tecnologías y participar en los procesos de gestión de la calidad en la edificación; realizar análisis, evaluación y certificaciones de eficiencia energética así como estudios de sostenibilidad en los edificios.

\section{Objetivos}

El tema pretende dar a conocer los modelos normalizados más reconocidos para implantar o mejorar la gestión de las organizaciones empresariales. Las normas podrán ser aprobadas o incluso adaptadas por organismos de normalización internacionales o nacionales.

1. En este tema la competencia a desarrollar implica el conocimiento de la legislación y normativa referente a la organización empresarial para implantar gestión integral.

2. Respecto a esta competencia, en este tema se pretende que el alumno aprenda los modelos para implantar la gestión de manera integrada en una organización. 


\section{Introducción}

En realidad, en la gestión empresarial, los directivos de hoy aplican ideas casi tan viejas como el propio ser humano. Pero al mismo tiempo, están muy atentos a los nuevos postulados... [1]

Los modelos de gestión que se estudian a continuación se presentan con una referencia expresa a sus requisitos de manera esquemática y una breve explicación de su contenido. Estas normas no son de aplicación exclusiva en empresas cuya actividad se desarrolla principalmente en el sector de la construcción. Estas son normas que han sido y son las más implantados en empresas de todos los sectores económicos [2] y también como no, entre empresas de construcción [3], promoción y empresas de arquitectura técnica/ingeniería de edificación [4].

Se considera función del representante de la dirección para la implantación de un sistema de gestión conocer a la perfección la propia organización y sus procesos, así como proponer el modelo o modelos de gestión más adecuados a las necesidades estratégicas de la empresa del sector de la construcción. Para ello se necesita de un técnico competente para identificar los procesos, así como definir los requisitos del modelo o modelos de gestión a implantar.

Recomendaciones para la correcta implantación de un sistema de gestión en la empresa:

a) Un sistema de gestión debe estar particularizado para cada empresa, porque dependerá de sus recursos humanos y técnicos, así como de los procesos necesarios para realizar el producto/servicio.

b) Un sistema de gestión debe considerarse como algo dinámico. Debe desarrollarse, implantarse, mantenerse y mejorarse, según el caso.

c) El seguimiento y control de los resultados de ejecución relacionados con los económicos puede ser considerado como un buen instrumento para motivar y alentar la implantación del sistema de gestión.

d) El nivel de implantación de un sistema de gestión en una empresa dependerá en gran medida del interés de la Dirección.

e) Cualquier persona involucrada con la empresa deberá estar bien informada $\mathrm{o} / \mathrm{y}$ formada para que no aparezcan reticencias al cambio. 


\section{Contenido}

\subsection{Modelos para la gestión de la calidad}

Los modelos o sistemas de gestión para la calidad de una organización fueron normas voluntarias que desde los años 80 han tenido más aceptación entre los empresarios, por esa razón también han sido las que más han evolucionado adaptándose a las necesidades de sectores concretos, como el modelo de capacitación profesional, para el sector de la construcción, adaptándose con los contenidos de otras normas, como las ISO 9001, o bien adaptándose a niveles más altos de exigencias de calidad como es el modelo para la autoevaluación EFQM2010.

\subsubsection{Modelo CPC. Capacitación Profesional Certificada [5]}

Los requisitos de este modelo de gestión se basan en exigencias sobre gestión de calidad, gestión de residuos y gestión de riesgos laborales en las obras de construcción. Se considera como la primera propuesta normalizada de gestión integrada para empresas del sector de la construcción elaborada por el Instituto Tecnológico de la Construcción de la Comunidad Valenciana (AIDICO).

Los requisitos a cumplir:

0. Introducción

1.1. Requisitos generales

1.2. Requisitos de documentación

2.1. Política de gestión

2.2. Funciones y responsabilidades

3.1. Gestión de los recursos humanos

3.2. Infraestructura

4. Realización del producto (PAC)

4.1. Planificación de la obra

4.2. Revisión de los requisitos relacionados de la obra

4.3. Compras

4.4. Ejecución de la obra y entrega al cliente

4.4.1. Control de la obra

4.4.2. Propiedad del cliente

5. Control del producto y del servicio no conforme 


\subsubsection{Modelo UNE EN-ISO 9001:2008. Requisitos para la gestión de la calidad}

El modelo de gestión propuesto por la ISo (International Organization for Standarization) es el más implantado en España, según revela el último informe del 2008, [2] por lo que es el tercer país del mundo por número de certificados de sistemas de gestión de la calidad según la normas ISO 9001. Un total de 68.730 certificados emitidos hasta 2008 le hacen merecedor de un tercer puesto según su clasificación mundial por países y un segundo puesto según su clasificación Europea, por detrás de Italia.

Esto nos demuestra la popularidad y el interés que las empresas muestran por implantar este modelo, lo cual es debido a varias razones: la primera, es que fue el primer sistema normalizado internacional que propuso unos requisitos para gestionar con calidad una organización; la segunda, es que tiene muchos años de experiencia y las mejoras de la propia norma le han hecho dirigirse hacia todos los sectores económicos, aunque en un principio tenía una orientación hacia la industria.

La norma ISO 9001, ha sido adaptada por la Unión Europea como norma EN y a su vez adaptada por España con una norma UNE y por ello traducida al castellano, por ese motivo su nomenclatura final queda como UNE EN-ISO 9001:2008, esto es así para cada uno de los estados miembros de la Unión Europea.

El modelo de gestión basado en la ISO 9001 propone como principio que las empresas deben gestionarse según sus procesos [7] y promocionar la mejora continua de los mismos para aumentar la satisfacción del cliente.

Los requisitos que debe cumplir:

0 . Introducción

0.1 . Generalidades

0.2 . Enfoque basado en procesos

0.3. Relación con la Norma ISO 9004

0.4. Compatibilidad con otros sistemas de gestión

1. Objeto y campo de aplicación

1.1. Generalidades

1.2. Aplicación

2. Referencias normativas

3. Términos y definiciones

4. Sistema de gestión de la calidad

4.1. Requisitos generales

4.2. Requisitos de la documentación

4.2.1. Generalidades

4.2.2. Manual de calidad 
4.2.3. Control de documentos

4.2.4. Control de los registros

5. Responsabilidad de la dirección

5.1. Compromiso de la dirección

5.2. Enfoque al cliente

5.3. Política de calidad

5.4. Planificación

5.4.1. Objetivos de la calidad

5.4.2. Planificación del sistema de gestión de calidad

5.5. Responsabilidad, autoridad y comunicación

5.5.1. Responsabilidad y autoridad

5.5.2. Representante de la dirección

5.5.3. Comunicación interna

5.6. Revisión por la dirección

5.6.1. Generalidades

5.6.2. Información de entrada para la revisión

5.6.3. Resultados de la revisión

6. Gestión de los recursos

6.1. Provisión de recursos

6.2. Recursos humanos

6.2.1. Generalidades

6.2.2. Competencia, formación y toma de conciencia

6.3. Infraestructura

6.4. Ambiente de trabajo

7. Realización del producto

7.1. Planificación de la realización del producto

7.2. Procesos relacionados con el cliente

7.2.1. Determinación de los requisitos relacionados con el producto

7.2.2. Revisión de los requisitos relacionados con el producto

7.2.3. Comunicación con el cliente

7.3. Diseño y desarrollo

7.3.1. Planificación del diseño y desarrollo

7.3.2. Elementos de entrada para el diseño y desarrollo

7.3.3. Resultados del diseño y desarrollo

7.3.4. Revisión del diseño y desarrollo

7.3.5. Verificación del diseño y desarrollo

7.3.6. Validación del diseño y desarrollo

7.3.7. Control de los cambios del diseño y desarrollo

7.4. Compras

7.4.1. Proceso de compras

7.4.2. Información de las compras

7.4.3. Verificación de los productos comprados 
7.5. Producción y prestación del servicio

7.5.1. Control de la producción y de la prestación del servicio

7.5.2. Validación de los procesos de la producción y de la prestación del servicio

7.5.3. Identificación y trazabilidad

7.5.4. Propiedad del cliente

7.5.5. Preservación del producto

7.6. Control de los equipos de seguimiento y de medición

8. Medición, análisis y mejora

8.1. Generalidades

8.2. Seguimiento y medición

8.2.1. Satisfacción del cliente

8.2.2. Auditoria interna

8.2.3. Seguimiento y medición de los procesos

8.2.4. Seguimiento y medición del producto

8.3. Control del producto no conforme

8.4. Análisis de datos

8.5. Mejora

8.5.1. Mejora continua

8.5.2. Acción correctiva

8.5.3. Acción preventiva

Comentarios respecto a cada uno de los apartados de la norma:

- Apartado 4: Requisitos Generales y Requisitos de la documentación. En este apartado se tendrá que dejar claro cómo se define el sistema de gestión, los documentos que contiene y cómo estos se encuentran relacionados. Además también hay que identificar los procesos que la empresa desarrolla para realización de sus productos/obras/servicios, indicando la posibilidad de excluir o no el proceso de diseño. Esta identificación servirá para presentar el mapa del proceso, diagrama por el cual se explican las interacciones que existen entre ellos.

- Apartado 5: Requisitos sobre las responsabilidades de la Dirección. Si la dirección y los mandos intermedios están comprometidos con el sistema, se asegura el éxito de la implantación del mismo, porque realmente servirá como herramienta para planificar (la política de la empresa, los objetivos a alcanzar, el organigrama de la empresa necesario, el plan de implantación, etc.), controlar (controles operacionales, controles de gestión, revisión por la dirección) y mejorar los errores detectados.

- Apartado 6: Requisitos sobre la gestión de los recursos. Entendemos por recursos, todos aquellos medios técnicos y humanos que necesita la empresa para desarrollar sus servicios, obras, productos. Por lo que en este apartado se deberá tener definido el método para el aprovisionamiento de los mismos; es decir, la compra o subcontratación. Pero además también se tendrá que tener en cuenta el ambiente de trabajo para los trabajadores. 
- Apartado 7: Requisitos para la realización del producto/servicio. Este apartado de la norma afecta principalmente a la parte productiva de la empresa; por ello, dependerá en gran medida de su actividad principal. Pero siempre deberemos tener presente las fases de Diseño-Compras-Ejecución-Control.

- Apartado 8: Requisitos para la mejora continua. Este apartado de la norma exige la medición y análisis de los resultados, con el fin implantar la mejora continua tanto en la producción como en el sistema, para tener siempre presente la satisfacción del cliente.

\subsubsection{Modelo EFQM. Modelo de Excelencia Europeo}

Modelo de gestión propuesto por The European Foundation for Quality Management (EFQM). Organización que fue fundada en 1988 por un grupo de 14 directivos de empresas establecidas en Europa, los cuáles estaban convencidos de la necesidad de crear una organización europea para promocionar estándares más altos de gestión a través del intercambio de experiencias y el reconocimiento mutuo. Posteriormente la misión y los miembros de la EFQM se han extendido, siendo en España su referente El Club Excelencia en Gestión que fue fundado el 11 de abril de 1991.

El nuevo modelo [9] no normalizado EFQM de Excelencia ${ }^{\circledR}$ que se basa en la autoevaluación ha sido revisado y presentado en septiembre 2009, incluye tendencias emergentes y temas de interés como son creatividad e innovación, sostenibilidad, gobernanza corporativa, agilidad organizacional, gestión del riesgo, promoción de productos y servicios y gestión de los proveedores.

Al igual que su versión anterior, la del 2003 está basada en 8 conceptos fundamentales, los cuales se presentan de una manera más estructurada. Lo que no cambia es su intención de alcanzar de manera integrada el estatus de ser excelente. Sin definir de manera predeterminada la prioridad entre ellos, es la empresa quien dependiendo de su situación e interés de futuro marcará sus prioridades. Los 8 conceptos fundamentales son:

- Lograr resultados equilibrados.

- Añadir valor para los Clientes.

- Liderar con visión, inspiración e integridad.

- Gestionar por procesos.

- Alcanzar el éxito mediante las personas.

- Favorecer la creatividad y la innovación.

- Desarrollar alianzas.

- Asumir la responsabilidad de un futuro sostenible.

El modelo en sí son 9 criterios para los cuales se define una ponderación sencilla y equilibrada. Son los 4 criterios de resultados y los 5 de agentes; ambas partes serán valoradas al $50 \%$ respectivamente. 
Cinco de ellos se denominan «agentes» y comprenden la totalidad de las áreas de gestión de la organización (lo que la organización hace y cómo lo hace). Los cuatro restantes reflejan los resultados que la organización alcanza, relativos a sus clientes, empleados, sociedad y objetivos estratégicos o clave. La lógica del modelo está basada en que la consecución de resultados excelentes en los cuatro ámbitos de gestión anteriores (clientes, empleados, sociedad y estrategia) está directamente relacionada con la capacidad de liderazgo, la calidad de la estrategia y su despliegue a través de las personas, partners, recursos y procesos.

Los 9 criterios:
1. Liderazgo
2. Estrategia
3. Personas
4. Alianzas y recursos
5. Procesos, productos y servicios
6. Resultados en los clientes
7. Resultados en las personas
8. Resultados en la sociedad
9. Resultados clave

Para desarrollar la autoevaluación se propone el método REDER (en inglés radar). La matriz de puntuación REDER se aplica para evaluar los documentos de solicitud que se presentan al EFQM para alcanzar el Premio Europeo a la Calidad. La puntuación que se puede obtener por el cumplimiento de cada criterio es de 100 puntos, excepto los criterios 7 y 9 cuya puntuación es sobre 150 .

Para la evaluación del nivel de calidad que alcanza una organización, respecto a los resultados, se evaluarán dos elementos principales: 1) la relevancia y utilidad de los resultados; y 2) los aspectos de rendimiento de tendencias, objetivos, comparaciones y causas. Respecto a los agentes se evaluará: 1) el enfoque; 2) el despliegue; 3) evaluar, revisar y perfeccionar.

\subsection{Modelos para la gestión medioambiental de la organización}

Los modelos voluntarios de gestión medioambiental Iso 14001 se desarrollaron a partir de la gran aceptación que tuvieron las normas de calidad, por lo que cada vez su estructura permite una mayor y mejor integración entre estas dos normas e incluso auditorías conjuntas. Además desde la Unión Europea se considera que es esencial fomentar una participación más amplia en el sistema comunitario de gestión y auditoría medioambientales (EMAS). En cuya última versión se propone una integración entre la Iso 14001 y el Reglamento EMAS. 


\subsubsection{Modelo UNE EN-ISO 14001:2004. Requisitos para la gestión medioambiental}

La norma Iso 14001 [10] es voluntaria y de aplicación a cualquier organización, en base a la cual una empresa puede ser certificada por entidades independientes.

Esta norma internacional especifica los requisitos para un sistema de gestión ambiental que le permita a una organización definir e alcanzar una política y unos objetivos que tengan en cuenta los requisitos legales y los aspectos ambientales significativos en los que afecte su actividad.

Los requisitos que debe cumplir:

Introducción

1. Objeto y campo de aplicación

2. Normas para consulta

3. Términos y definiciones

4. Requisitos del sistema de gestión ambiental

4.1. Requisitos generales

4.2. Política ambiental

4.3. Planificación

4.3.1. Aspectos ambientales

4.3.2. Requisitos legales y otros requisitos

4.3.3. Objetivos, metas y programas

4.4. Implementación y operación

4.4.1. Recursos, funciones, responsabilidad y autoridad

4.4.2. Competencia, formación y toma de conciencia

4.4.3. Comunicación

4.4.4. Documentación

4.4.5. Control de documentos

4.4.6. Control operacional

4.4.7. Preparación y respuesta ante emergencias

4.5. Verificación

4.5.1. Seguimiento y medición

4.5.2. Evaluación del cumplimiento legal

4.5.3. No conformidad, acción correctiva y acción preventiva

4.5.4. Control de los registros

4.5.5. Auditoría interna

4.6. Revisión por la dirección

El contenido de la norma incluye varios apartados, pero los requisitos concretamente se definen a partir del apartado 4.2 hasta el 4.6. Por lo que el propósito de cada uno de ellos se resume a continuación [11]: 
4.2- Política. En este apartado la empresa define su compromiso para prevenir la contaminación debido a su propia actividad y plantea las intenciones para mejorar su gestión con ese fin. Además de asegurar el cumplimiento de la legislación vigente que le afecte.

4.3- Planificación. En este apartado se deben identificar según su actividad los aspectos medioambientales e incluso aquellos que puedan ser significativos para establecer e implantar procedimientos para su seguimiento y control. Además, también se exige identificar y actualizar los requisitos legales que son de aplicación y establecer su implantación. Así como, se deben establecer periódicamente los objetivos, metas y programas en función del tipo y actividad de la empresa. En él se tendrán que indicar además los medios necesarios para alcanzarlos.

4.4- Implantación. En este apartado la norma exige que se disponga de los recursos necesarios, que se definan las funciones a cada puesto de trabajo, que se les asigne responsabilidades a las personas, que las personas que asumen estos puestos sean competentes y que se les conciencie y forme según las necesidades. Además, la organización debe establecer canales de comunicación internos y externos para asegurar que toda la información relacionada con el sistema de gestión ambiental se transmite adecuadamente a todas las partes interesadas. La empresa debe crear y controlar la distribución, el archivo y mantenimiento de la documentación necesaria para definir y demostrar el cumplimiento del sistema de gestión. La implantación del sistema no estará completa si no se tienen controlados los aspectos medioambientales, por lo que en este apartado la empresa establecerá las inspecciones/controles necesarios para tener acotados los riesgos de cada aspecto medioambiental identificado. También tendremos que tener previsión ante posibles emergencias, para ello la empresa definirá las acciones para su prevención, control y actuación necesarios en caso de accidentes o emergencias.

4.5- Verificación. El objeto de este apartado consiste en establecer los procedimientos necesarios para controlar y medir (toma de datos) regularmente las características clave de operaciones y actividades que puedan provocar un impacto significativo sobre el medio ambiente, así como fijar las normas que deben cumplirse para llevar a cabo el mantenimiento y calibración de los equipos de medición de parámetros ambientales. También se tendrán que definir los procedimientos para poder demostrar el cumplimiento de los requisitos legales. Además, se deberá definir el método operativo para identificar, comunicar y gestionar correctamente los fallos o errores del sistema de gestión con acciones correctivas o bien preventivas para evitar fallos potenciales. Es necesario también controlar todos los registros que demuestran el cumplimiento del sistema, anteriormente ya se había propuesto para el control documental la necesidad de establecer un procedimiento que controle documentos, por lo que el control de los registros podría estar incluido en este mismo o definir otro exclusivo para controlar los registros que demuestran el cumplimiento del sistema. La empresa deberá diseñar un programa de evaluación de forma periódica para demostrar la correcta implantación, cumplimiento de los procedimientos del sistema, que constate la eficacia del sistema de gestión ambiental. 
4.6- Revisión por la dirección. es obligación de la alta dirección evaluar la efectividad y la adecuación del sistema de gestión ambiental según las necesidades de la empresa, en base a los resultados obtenidos de la detección de no conformidades, resultados de las acciones correctivas, de los informes finales de auditorías internos y externos, etc. Todo ello puede justificar la necesidad de cambios y modificaciones en el sistema de gestión.

\subsubsection{Reglamento EMAS $1221 / 2009$. Sistema de gestión y auditorías medioambientales}

El pasado 22 de diciembre se publicó el nuevo reglamento por el Parlamento Europeo relativo a la participación voluntaria de organizaciones en un sistema comunitario de gestión y auditorías medioambientales (EMAS. EcoManagement and Audit Sheme).

El objetivo de EMAS [12] consiste en promover mejoras continuas del comportamiento medioambiental de las organizaciones mediante el establecimiento y la aplicación por su parte de sistemas de gestión medioambiental; la evaluación sistemática, objetiva y periódica del funcionamiento de tales sistemas; la difusión de información sobre comportamiento medioambiental; el diálogo abierto con el público y otras partes interesadas; y la implicación activa del personal en las organizaciones, así como una formación adecuada.

Los requisitos del sistema de gestión medioambiental aplicables con arreglo a EMAS son los establecidos en la sección 4 de la norma EN ISO 14001:2004, y además, otros requisitos adicionales, según vemos en la tabla siguiente:

A-Requisitos ISO 14001:2004

Introducción

1. Objeto y campo de aplicación

2. Normas para consulta

3. Términos y definiciones

4. Requisitos del sistema de gestión ambiental

4.1. Requisitos generales

4.2. Política ambiental

4.3. Planificación

4.3.1. Aspectos ambientales

4.3.2. Requisitos legales y otros requisitos

4.3.3. Objetivos, metas y programas

4.4. Implementación y operación
B-Requisitos adicionales EMAS

B.1. Análisis medioambiental

B.2. Respeto de la legislación

B.3. Comportamiento medioambiental 
4.4.1. Recursos, funciones, responsabilidad y autoridad

4.4.2. Competencia, formación y toma de conciencia

B.4. Implicación de los trabajadores

4.4.3. Comunicación

B.5. Comunicación

1) Demostrar un diálogo abierto

2) Franqueza, transparencia y perioricidad

3) Flexibilidad

4.4.4. Documentación

4.4.5. Control de documentos

4.4.6. Control operacional

4.4.7. Preparación y respuesta ante emergencias

\subsection{Verificación}

4.5.1. Seguimiento y medición

4.5.2. Evaluación del cumplimiento legal

4.5.3. No conformidad, acción correctiva y acción preventiva

4.5.4. Control de los registros

4.5.5. Auditoria interna

4.6. Revisión por la dirección

Figura 1: Requisitos EMAs 2009

Para el apartado B1 del reglamento el análisis medioambiental consiste en:

1. Indicación de los requisitos legales aplicables en materia de medio ambiente.

2. Indicación de todos los aspectos medioambientales directos e indirectos que tengan un impacto ambiental significativo, cualificados y cuantificados según convenga, y compilación de un registro de los catalogados como significativos.

3. Descripción de los criterios para la evaluación del carácter significativo del impacto ambiental.

4. Examen de todas las prácticas y procedimientos de gestión medioambiental existentes.

5. Evaluación de la información obtenida a partir de las investigaciones sobre incidentes previos.

El requisito B5 Comunicación implica la presentación de informes medioambientales, los cuales deberán ser coherentes para poder realizar estudios de comparación por sectores, por lo que recomienda el siguiente contenido:

1. Introducción. 
2. Declaración medioambiental:

a) una descripción clara e inequívoca del registro de la organización en EMAS y un resumen de sus actividades, productos y servicios y de su relación con organizaciones afines, en su caso;

b) la política medioambiental y una breve descripción del sistema de gestión medioambiental de la organización;

c) una descripción de todos los aspectos medioambientales directos e indirectos significativos que tengan como consecuencia un impacto ambiental significativo de la organización, y una explicación de la naturaleza de este impacto en relación con dichos aspectos (apartado 2 del anexo I);

d) una descripción de los objetivos y metas medioambientales en relación con los aspectos e impactos ambientales significativos;

e) un resumen de la información disponible sobre el comportamiento de la organización respecto de sus objetivos y metas medioambientales en relación con su impacto ambiental significativo; deben comunicarse los indicadores básicos y otros indicadores existentes de comportamiento medioambiental que sean pertinentes, como se establece en la sección C;

f) otros factores relativos al comportamiento medioambiental, incluyendo el comportamiento respecto a las disposiciones legales en relación con sus impactos ambientales significativos;

g) una referencia a los requisitos legales aplicables en materia de medioambiente;

h) el nombre y número de acreditación o autorización del verificador medioambiental y la fecha de la validación.

\section{Indicadores}

1) Introducción.

2) Indicadores básicos:

a) Los indicadores básicos deben aplicarse a todos los tipos de organizaciones. Se centran en el comportamiento en los siguientes ámbitos medioambientales clave:

I) eficiencia energética,

II) eficiencia en el consumo de materiales,

III) agua,

IV) residuos, 

v) biodiversidad,
VI) emisiones.

b) Cada uno de los indicadores básicos está compuesto de:

I) una cifra A, que indica el impacto/consumo total anual en el campo considerado,

II) una cifra $\mathrm{B}$, que indica la producción anual global de la organización,

III) una cifra $\mathrm{R}$, que indica la relación $\mathrm{A} / \mathrm{B}$.

Cada organización debe comunicar los tres elementos de cada indicador.

c) La indicación del impacto/consumo total anual en el ámbito considerado, cifra A, se comunicará como sigue:

I) sobre la eficiencia energética:

- por lo que se refiere al «consumo directo total de energía», el consumo anual total de energía, expresado en MWh o GJ,

- por lo que se refiere al «consumo total de energía renovable», el porcentaje del consumo anual total de energía (eléctrica y térmica) producida por la organización a partir de energía procedente de fuentes renovables;

II) sobre la eficiencia en el consumo de materiales:

- el «gasto máximo anual de los distintos materiales utilizados» (con exclusión de los productos energéticos y el agua) debe expresarse en toneladas $\mathrm{T}$;

III) sobre el agua:

- el «consumo total anual de agua» debe expresarse en $\mathrm{m}^{3}$;

IV) sobre los residuos:

- la «generación total anual de residuos», desglosada por tipo, debe expresarse en toneladas,

- la «generación total anual de residuos peligrosos» debe expresarse en kilogramos o toneladas;

v) sobre la biodiversidad:

- la «ocupación del suelo» debe expresarse en $\mathrm{m}^{2}$ de superficie construida;

VI) sobre las emisiones:

- las «emisiones anuales totales de gases de efecto invernadero», incluidas al menos las emisiones de $\mathrm{CO}_{2}, \mathrm{CH}_{4}, \mathrm{~N}_{2} \mathrm{O}, \mathrm{HFC}, \mathrm{PFC}$ y SF , deben expresarse en toneladas equivalentes de $\mathrm{CO}_{2}$,

- las «emisiones anuales totales de aire», incluidas al menos las emisiones de $\mathrm{SO}_{2}, \mathrm{NO}_{x}$ y $\mathrm{PM}$, deben expresarse en kilogramos o toneladas. 
Además de los indicadores definidos anteriormente, una organización podrá recurrir también a otros indicadores para expresar el impacto/consumo total anual en el campo considerado.

d) La indicación de la producción anual global de la organización, cifra $\mathrm{B}$, es la misma para todos los campos pero se adapta a los distintos tipos de organizaciones, en función de su tipo de actividad, y se comunicará como sigue:

I) para las organizaciones que operan en el sector de la producción (industria), se indicará el valor añadido bruto anual total expresado en millones de euros (EUR millones) o la producción física anual expresada en toneladas, o, en el caso de organizaciones pequeñas, el volumen de negocios anual total o número de trabajadores,

II) para las organizaciones de sectores no productivos (administración/servicios), se relacionará con el tamaño de la organización, expresado en número de trabajadores.

Además de los indicadores definidos anteriormente, una organización podrá utilizar también otros indicadores para expresar su producción anual global.

4. Otros indicadores de comportamiento medioambiental pertinentes.

5. Disponibilidad pública.

6. Responsabilidad local

\subsection{Modelos para la gestión de la prevención de los riesgos laborares de la organización}

\subsubsection{Modelo según OHSAS 18001:2007 Requisitos del sistema de gestión de seguridad y salud laboral [13]}

Occupational Safety and Health Administration. United Stated Department of labor lideró la creación de la norma OHSAS 18001 Requisitos para la gestión de la prevención de riesgos laborales, la cual fue creada en 2007 a partir de un consenso entre diferentes entidades de normalización, entre las que se encontraba AENOR con la UNE 81900 Norma experimental para la prevención de riesgos laborales. El objetivo principal fue intentar eliminar confusión en el lugar de trabajo debido a la proliferación de sistemas o normas para la prevención de riesgos laborales por multitud de entidades de diferentes países.

La OHSAS define los requisitos para la gestión de la prevención de los riesgos laborales, que le permita a una empresa controlar los riesgos y mejorar su desarrollo. 
No define criterios específicos de cómo desarrollarlo, ni tampoco define en detalle el diseño del sistema de gestión.

Requisitos:

4.1. Requisitos generales

4.2. Política

4.3. Planificación

4.3.1. Identificación, valoración riesgo y determinar control

4.3.2. Legislación de aplicación

4.3.3. Objetivos, funciones y organización

4.4. Implantación y operaciones

4.4.1. Recursos y responsabilidades

4.4.2. Competencias y formación

4.4.3. Comunicación

4.4.4. Documentación

4.4.5. Control documentos

4.4.6. Control de las operaciones/actividades

4.4.7. Planes de emergencia

4.5. Control

4.5.1. Medición y control

4.5.2. Evaluar el cumplimiento

4.5.3. Investigación de incidentes (no conformidad/acción correctiva/ acción preventiva)

4.5.4. Control de los registros

4.5.5. Auditorías internas

4.6. Revisión por la dirección

Como se puede comprobar, su estructura es compatible con otras normas de gestión, como por ejemplo las normas para la gestión Iso 9001 (calidad) y ISO 14001 (medioambiental), de manera que se permita la posibilidad de integrar las tres en los sistemas de gestión de las empresas si lo desea. 


\subsection{Modelos para la gestión de la innovación de la organización}

\subsubsection{Modelo para la gestión $\mathrm{I}+\mathrm{D}+\mathrm{i}$ : UNE 166002:2006 Requisitos del sistema de gestión $\mathrm{I}+\mathrm{D}+\mathrm{i}[14]$}

La innovación tecnológica que se realiza en un país contribuye, cada vez más y de forma más acusada, para determinar el crecimiento económico, los niveles de bienestar y su competitividad internacional. Dada su compleja naturaleza necesita de un marco normativo que la sistematice y apoye la optimización de estas actividades.

Requisitos:

4.1 Modelo y sistema de gestión de la I+D+i

4.1.1. Generalidades

4.1.2. Documentación

4.1.2.1. Control de documentos

4.1.2.2. Control de los registros

4.2 Responsabilidad de la dirección

4.2.1. Compromiso de la dirección

4.2.2. Enfoque a las partes interesadas

4.2.3. Política de $\mathrm{I}+\mathrm{D}+\mathrm{i}$

4.2.4. Planificación

4.2.4.1. Objetivos de $\mathrm{I}+\mathrm{D}+\mathrm{i}$

4.2.4.2. Planificación del sistema de gestión de la $\mathrm{I}+\mathrm{D}+\mathrm{i}$

4.2.5. Responsabilidad, autoridad y comunicación

4.2.5.1. Unidad de gestión de la $\mathrm{I}+\mathrm{D}+\mathrm{i}$

4.2.5.2. Unidad de $\mathrm{I}+\mathrm{D}+\mathrm{i}$

4.2.5.3. Establecimiento y estructura de las unidades de $\mathrm{I}+\mathrm{D}+\mathrm{i}$ y de gestión de $\mathrm{I}+\mathrm{D}+\mathrm{i}$

4.2.5.4. Representante de la dirección

4.2.5.5. Comunicación interna

4.2.6. Revisión por la dirección

4.2.6.1. Generalidades

4.2.6.2. Información para la revisión

4.2.6.3. Resultados de la revisión

4.3 Gestión de los recursos

4.3.1. Provisión de recursos

4.3.2. Recursos humanos

4.3.2.1. Generalidades

4.3.2.3. Competencia, toma de conciencia y formación

4.3.3. Infraestructura 
4.3.4. Ambiente de trabajo

4.4 Actividades de $\mathrm{I}+\mathrm{D}+\mathrm{i}$

4.4.1. Herramientas

4.4.2. Identificación y análisis de los problemas

4.4.3. Análisis y selección de ideas de $\mathrm{I}+\mathrm{D}+\mathrm{i}$

4.4.4. Planificación, seguimiento y control de los proyectos

4.4.5. Transferencia y tecnología

4.4.6. Producto $\mathrm{I}+\mathrm{D}+\mathrm{i}$

4.4.7. Compras

4.4.8. Resultados del proceso

4.4.9. Protección y explotación de los resultados de las actividades $\mathrm{I}+\mathrm{D}+\mathrm{i}$

4.5 Medición, análisis y mejora

4.5.1. Generalidades

4.5.2. Auditoria interna

4.5.3. Seguimiento y medición del proceso de $\mathrm{I}+\mathrm{D}+\mathrm{i}$

4.5.4. Seguimiento y medición de los resultados del proceso de $\mathrm{I}+\mathrm{D}+\mathrm{i}$

4.5.5. Control de las desviaciones en los resultados esperados

4.5.6. Análisis de datos

4.5.7. Mejora

4.5.7.1. Mejora continua

4.5.7.2. Acción correctiva

4.5.7.3. Acción preventiva

Con el contenido de esta norma se pretende que una organización pueda:

- Fomentar las actividades de $\mathrm{I}+\mathrm{D}+\mathrm{i}$.

- Proporcionar directrices para organizar y gestionar eficazmente $\mathrm{I}+\mathrm{D}+\mathrm{i}$, como por ejemplo realizando:

- El análisis de la situación.

- Identificación y valoración de amenazas y oportunidades de la evolución tecnológica.

- Definición de los objetivos básicos de las actividades I+D+i.

- Selección y gestión de una cartera de proyectos.

- Asegurar que no se pierdan actividades susceptibles de generar tecnología propia.

Los requisitos especificados del sistema $\mathrm{I}+\mathrm{D}+\mathrm{i}$ de esta norma son complementarios a los requisitos de cualquier otro sistema de gestión implantado en una organización tales como: gestión de la calidad, gestión medioambiental, gestión ética y social, gestión de la seguridad, gestión del riesgo, etc. 


\subsection{Modelos para la gestión del conocimiento de la organización}

CwA 14924-1:2004 European Guide to good Practice in Knowledge Management

\subsubsection{Modelo según norma UNE 412001:2008 IN Guía práctica de gestión del conocimiento [15]}

Esta guía está elaborada a partir de la cWA 14924 European Guide to good Practice in Knowledge Management [16], revisada y adaptada por el Grupo de Trabajo Específico de Carácter Temporal AEN/GET 12 Gestión del Conocimiento de AENOR, compuesto por académicos, directivos y consultores.

En este caso particular la guía ofrece aportaciones sobre la europea y recomendaciones para su puesta en práctica en las organizaciones españolas, con un propósito claro de animar a la empresa española a emprender el camino de implantar la gestión del conocimiento organizativo y facilitar su recorrido.

Se basa en el nuevo enfoque del pensamiento económico: gestión del conocimiento para la innovación.

Contenido de la guía:

1. Objeto y campo de aplicación

2. Términos y definiciones

3. Gestión del conocimiento y cultura organizativa

4. Aspectos de la implantación de proyectos de gestión del conocimiento

5. Poniendo en marcha un proyecto de gestión del conocimiento

6. Medición de la gestión del conocimiento

7. Anexos informativos

Anexo A: Herramientas para la gestión del conocimiento

Anexo B: Herramientas útiles de gestión de personas para la gestión del conocimiento

Anexo C: Marco conceptual y evolución de la gestión del conocimiento

Anexo D: Bibliografía

Este nuevo enfoque está directamente relacionado con «el enfoque por procesos» que promulga la Norma de Calidad Iso 9001.

Si analizamos la gestión del conocimiento como un proceso de apoyo más en la gestión de la empresa, tendremos que tener en cuenta cinco actividades principales: Identificar, crear, almacenar, compartir y usar el conocimiento. En algunos casos las organizaciones pueden incluir otras actividades, como es el caso de filtrar y seleccionar el conocimiento. 
Identificar el conocimiento: en este paso las organizaciones deben pensar qué es lo que quieren lograr y el conocimiento que necesitan para ello. Se debe incluir un análisis enfocado a identificar los gaps o brechas para determinar el conocimiento que no se ha adquirido (sea tácito o implícito) a todos los niveles (estratégico, funcional, de procesos, personal, etc.). Esta información es vital para la toma de decisiones. Puntos de referencia a tener en cuenta los constituyen los requerimientos de los clientes, los pasos de los procesos, salidas de procesos que agregan valor. Las técnicas más utilizadas en la identificación del conocimiento son: tormenta de ideas, retroalimentación con los clientes, etc.

Crear conocimiento: descubrir cómo se crea el conocimiento en la organización, teniendo en cuenta los individuos y los grupos. Considerar el flujo de ideas en procesos de innovación y mejora, por ejemplo, en la creación de nuevos productos y servicios.

Almacenar el conocimiento: este paso es significativo en la construcción de activos de conocimiento, puesto que el conocimiento debe incorporarse a la organización para facilitar su re-utilización. Adquiere mayor relevancia en organizaciones donde existen pocos especialistas en diferentes temas de importancia, cuya pérdida podría ser negativa para la organización en caso de que se retiren o decidan abandonar la organización por cualquier motivo. Este efecto se atenuará en gran medida si la organización fue capaz de almacenar el conocimiento (procedimientos, manuales, mejores prácticas, sugerencias a proyectos ejecutados, etc.) de esos expertos, facilitándose su transferencia a otros.

Compartir el conocimiento: el objetivo de esta etapa está dirigido a transferir el conocimiento al lugar donde se necesita, en el momento adecuado y con la calidad requerida. El conocimiento se puede compartir de muchas formas. Se puede compartir mediante el registro en bases de datos, o distribuirlo en documentos. El conocimiento se distribuye para que otras personas puedan encontrarlo y lo utilicen en procesos que añadan valor. La mayoría del conocimiento se transmite de mejor forma de persona a persona mediante la colaboración, talleres, aprendizaje en el trabajo diario, etc. Las herramientas que facilitan este proceso son: Internet, intranets, bases de datos, comunidades de práctica, rotación de puestos de trabajo, seminarios, cursos, etc. Si no se acepta el conocimiento aportado por otros, es muy probable que no se logre el objetivo más importante de la GC: utilizar el conocimiento.

Utilizar el conocimiento: el conocimiento añade valor solamente cuando se utiliza en la organización. El exceso de conocimiento no se utiliza a plenitud, por ello es importante asegurarse de que las actividades que se realizaron previamente se ejecutaron de forma correcta. Utilizar el conocimiento determina las necesidades de la organización a este respecto y debe servir como referencia para la creación, almacenamiento y las formas de compartir conocimiento. Es posible que se descubran otras brechas cuando se aplica el conocimiento, por ello el proceso global de $\mathrm{GC}$ debe realizarse de forma continua para asegurar que se integra a la iniciativa GC.

Finalmente, se tendrá que considerar para su integración y desarrollo la necesidad de utilizar métodos y herramientas apropiados para la gestión del conocimiento. 


\subsection{Modelos para la gestión de la responsabilidad social corporativa de la organización}

\subsubsection{Modelo según SA 8000:2008 Requisitos para la responsabilidad social corporativa [17]}

La norma SA 8000:2008 es la tercera versión editada por la Social Accountability International (SAI). Institución no gubernamental que tiene como misión hacer cumplir los derechos humanos de los trabajadores en todo el mundo.

Requisitos:

Introducción

I Propósito y ámbito de aplicación

II Elementos normativos y su interpretación

III Definiciones

IV Requisitos de responsabilidad social: criterios

1. Trabajo infantil

2. Trabajos forzados

3. Salud y seguridad en el trabajo

4. Libertad de asociación y derecho de negociación colectiva

5. Discriminación

6. Medidas disciplinarias

7. Horario de trabajo

8. Remuneración

9. Sistemas de gestión

9.1. Política

9.2. Representante de la dirección

9.3. Representante de los trabajadores

9.4. Revisión por la Dirección

9.5. Planificación e implementación

9.6. La empresa está obligada a consultar el Documento Guía de la norma SA 8000

9.7. Registros del cumplimiento de los prov/sub

9.8. Disponer de procedimientos para la evaluación de contratistas, subcontratistas y subproveedores

9.9. Asegurar cumplimiento de la norma por los proveedores/subcontratistas y subproveedores

9.10. Exigencias de Seguridad Social del personal contratado por prov/sub

9.11-12. Identificación de no conformidades e inicio de acciones correctivas

9.13-14. Comunicación externa

9.15. Acceso para verificación

9.16. Registros 
SA 8000 (Social Accountability 8000) es una norma voluntaria, global y verificable para auditar y certificar el cumplimiento de la responsabilidad social corporativa. Se aplica tanto a empresas pequeñas como a las grandes que desean demostrar a los clientes y a todas las partes interesadas que sí les importa el bienestar de sus empleados. La esencia de la norma es la creencia de que todo lugar de trabajo debe ser administrado de manera tal que estén garantizados los derechos humanos básicos y que la gerencia está preparada para asumir la responsabilidad por ello.

La norma se basa en otras normas de derechos humanos internacionales existentes, entre ellas, la Declaración Universal de los Derechos Humanos y la Convención Internacional sobre los Derechos del Niño de la ONU. La norma SA 8000 establece pautas transparentes, medibles y verificables para certificar el desempeño de empresas en nueve áreas esenciales:

Trabajo infantil. Prohíbe el trabajo infantil (en la mayoría de los casos, niños de menos de 15 años de edad). Las empresas certificadas también deben asignar fondos para la educación de niños que podrían perder su trabajo a raíz de la aplicación de esta norma.

Trabajo forzado. No se puede exigir a los trabajadores que entreguen sus documentos de identidad ni que paguen «depósitos» como condición para el empleo.

Higiene y seguridad. Las empresas deben cumplir con normas básicas para un ambiente de trabajo seguro y saludable, entre ellas: agua potable, instalaciones sanitarias, equipo de seguridad aplicable y capacitación necesaria.

Libertad de asociación. Protege los derechos de los trabajadores de crear y participar en sindicatos y de gestionar convenios colectivos, sin miedo a represalias.

Discriminación. No se permite la discriminación por raza, casta, nacionalidad, religión, discapacidad, género, orientación sexual, pertenencia a un sindicato o afiliación política.

Prácticas disciplinarias. Prohíbe el castigo corporal, la coerción física o mental y el abuso verbal de los trabajadores.

Horario de Trabajo. Establece una semana de 48 horas como máximo, con un mínimo de un día libre por semana y un límite de 12 horas extras por semana remuneradas a una tarifa especial.

Remuneración. Los salarios pagados deben cumplir con todas las normas legales mínimas y proveer suficientes ingresos para cubrir las necesidades básicas, con por lo menos una parte de ingreso discrecional. 


\subsubsection{Modelo según Rs 10:2009 Sistema de gestión de la responsabilidad social [18]}

Utilizando como marco de referencia el proyecto de Norma Iso 26000, la Norma UNE 165010:2009 EX y la amplia bibliografía existente, AENOR propone las bases para implantar un sistema de gestión de la responsabilidad social basado en la metodología Planificar-Hacer-Verificar-Actuar, orientado a la mejora continua.

Requisitos:

4. Sistema de gestión de la responsabilidad social

4.1. Requisitos generales

4.2. Requisitos de documentación

4.2.1. Generalidades

4.2.2. Manual de responsabilidad social

4.2.3. Control de los documentos

4.2.4. Control de los registros

5. Responsabilidad de la dirección

5.1. Compromiso de la dirección

5.2. Enfoque a los grupos de interés

5.3. Política de responsabilidad social

5.4. Planificación

5.4.1. Objetivos, metas y programas

5.4.2. Planificación del sistema de gestión de la responsabilidad social

5.5. Responsabilidad, autoridad y comunicación

5.5.1. Responsabilidad y autoridad

5.5.2. Representante de la dirección

5.5.3. Comunicación

5.6. Requisitos legales y otros requisitos

5.7. Comunicación, información e implicación con los grupos de interés

5.8. Revisión del sistema por la dirección

5.8.1. Información de entrada para la revisión

5.8.2. Resultados de la revisión

6. Gestión de los recursos

6.1. Generalidades

6.2. Competencia, formación y toma de conciencia

7. Requisitos del sistema de responsabilidad social ante los grupos de interés

7.1. Generalidades

7.2. Requisitos de la organización ante los propietarios, accionistas, inversores y socios

7.2.1. Eficacia y eficiencia en la gestión

7.2.2. Gobierno de la organización

7.2.3. Transparencia informativa

7.2.4. Derechos de voto y representación

7.3. Requisitos de la organización ante los empleados

7.3.1. No discriminación

7.3.2. Derecho a la intimidad 
7.3.3. Trabajo forzoso

7.3.4. Trabajo infantil

7.3.5. Salud y seguridad

7.3.6. Entornos accesibles

7.3.7. Asociación y negociación

7.3.8. Salario

7.3.9. Contrato de trabajo

7.3.10. Formación, empleabilidad y carrera profesional

7.3.11. Conciliación de la vida personal, familiar y laboral

7.3.12. Respeto a la dignidad del trabajador

7.3.13. Mecanismos de comunicación

7.4. Requisitos de la organización ante los clientes, usuarios y consumidores

7.4.1. Promociones y publicidad

7.4.2. Contratos

7.4.3. Confidencialidad

7.4.4. Honestidad

7.4.5. Atención al cliente y postventa

7.4.6. Bienes y servicios socialmente responsables

7.5. Requisitos de la organización ante los proveedores de productos y servicios

7.5.1. Fomento de los principios de la responsabilidad social en la cadena de suministro

7.5.2. Formalización y cumplimiento del contrato

7.5.3. Honestidad

7.6. Requisitos de la organización en sus alianzas o colaboraciones

7.7. Requisitos de la organización ante los competidores

7.8. Requisitos de la organización ante la administración

7.8.1. Colaboración y transparencia

7.8.2. No injerencia

7.8.3. Obligaciones fiscales

7.8.4. Honestidad

7.9. Requisitos de la organización ante la comunidad/sociedad

7.9.1. Compromiso

7.9.2. Promoción del desarrollo local

7.9.3. Comunidades indígenas

7.9.4. Seguridad del producto y servicio

7.9.5. Respeto a los animales

7.10. Requisitos de la organización ante el medio ambiente

7.10.1. Prevención de la contaminación

7.10.2. Cambio climático

7.10.3. Uso eficiente de los recursos

7.10.4. Preservación de los ecosistemas y de la biodiversidad

8. Medición, análisis y mejora

8.1. Generalidades

8.2. Seguimiento y medición de las actividades de gestión en el ámbito de la responsabilidad social

8.3. Análisis de datos

8.4. Evaluación del cumplimiento legal

8.5. Satisfacción de los grupos de interés

8.6. No conformidad, acción correctiva y acción preventiva

8.7. Auditoría interna 
Los requisitos para el sistema de la gestión de la responsabilidad social son compatibles con otras normas de gestión como la de calidad UNE-EN ISO 9001, la ambiental UNE-EN ISO 14001, o la de seguridad y salud laboral oHSAS 18001. De esta forma se facilita la posibilidad de implantar o evolucionar hacia una gestión integrando estrategias en un modelo único.

Con este modelo de gestión se pretende que la empresa respete los derechos humanos básicos recogidos en documentos y normativa internacional como son:

- El respeto a la dignidad humana.

- La supresión de la explotación infantil.

- La supresión del trabajo forzoso.

- La no discriminación e igualdad ante la ley.

- La igualdad de oportunidades.

- La protección del medio ambiente en un marco de desarrollo sostenible.

\section{Referencias}

[1] Cien años de Management, Asociación Española para la Calidad. Noviembre 2000.

[2] The ISO survey of certifications 2008. International Organization for Standarization.

[3] Análisis de un Sistema de la Calidad para pequeñas y medianas empresas constructoras. Gallego Navarro, Teresa. 1997.

[4] Gestión de la calidad en la arquitectura técnica. Consejo General de la Arquitectura Técnica de España. 2008.

[5] CPC. Capacitación Profesional Certificada. Reglamento general de la marca CPC 2006. AIDICO.

[6] UNE-EN ISO 9001: 2008. Requisitos para la gestión de la calidad.

[7] UNE-EN ISO 9000: 2005. Sistemas de gestión de la calidad. Fundamentos y vocabulario.

[8] EFQM. Modelo de Excelencia Europeo.

[9] Guía de Transición al Modelo EFQM 2010.

[10] UNE-EN ISO 14001:2004. Requisitos para la gestión medioambiental.

[11] Cómo implantar un sistema de gestión ambiental según la norma iso 14001: 2004. Javier Granero Castro, Miguel Ferrando Sánchez. 2a edición. 2007.

[12] Reglamento EMAS- 1221/2009.

[13] OHSAS 18001 Requisitos para la gestión de la prevención de riesgoslaborales.

[14] UNE 166001:2006 Requisitos de gestión de la I+D+i.

[15] UNE 412001:2008 IN Guía práctica de gestión del conocimiento.

[16] CWA 14924:2004 European Guide to good Practice in Knowledge Management

[17] SA 8000:2008. Responsabilidad social corporativa.

[18] Rs 10 Sistema de gestión de la responsabilidad social. Requisitos. 


\section{Webs}

Asociación Española de Normalización www.aenor.es

Instituto tecnológico de la construcción de la Comunidad Valenciana www.aidico.es The European Foundation for Quality Management (Bélgica) http://www.efqm.org Club de la excelencia en gestión (España) http://www.clubexcelencia.org/

Occupational Safety and Health Administration. Department of labor (United States of America) http://www.osha.gov/

Social Accountability International http://www.sa-intl.org/

El Instituto Universitario de Investigación en Administración del Conocimiento e Innovación de Empresas (IADE) http://www.iade.org/ 


\section{TEMA 3}

\section{Gestión por procesos}

1. Mapa conceptual

2. Competencias

3. Objetivos

4. Introducción

5. Gestión por procesos según las normas Iso 9001:2008

6. Gestión por procesos según el modelo EFQM 2010

7. La definición de un sistema de gestión basado en procesos para el sector de la edificación

7.1. Determinación o identificación de los procesos necesarios en edificación

7.2. Determinar la secuencia o interacción entre los procesos en edificación

7.3. Seguimiento de los procesos

8. Referencias

9. Webs 


\section{Mapa conceptual}

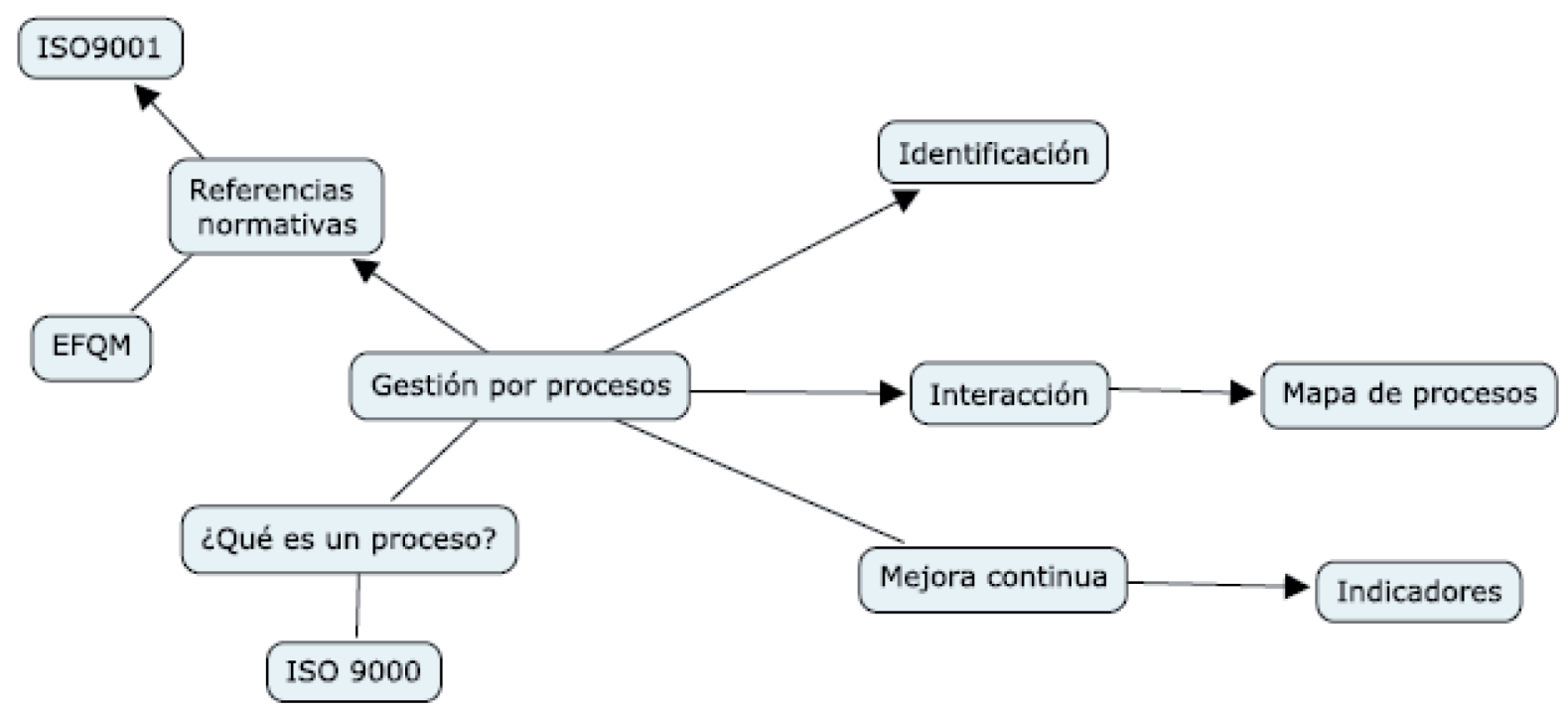

\section{Competencias}

OP18. Gestionar las nuevas tecnologías edificatorias y participar en los procesos de gestión de la calidad en la edificación.

\section{Objetivos}

El tema pretende enseñar al alumno a:

- Analizar de manera general las actividades que desarrollan las empresas del sector de la edificación para cumplir sus contratos (servicios, proyectos, obra).

- Analizar aquellas actividades de la empresa que no están directamente relacionadas con la producción o desarrollo de sus servicios.

- Enseñar al alumno de manera conjunta las actividades de la empresa para que se entienda como organización.

- Identificar grupo de actividades como procesos.

- Saber mostrar la interacción entre los procesos.

- Definir métodos para medir, analizar y mejorar los procesos. 


\section{Introducción}

Los empresarios del sector de la construcción se encuentran continuamente preocupados por conseguir la diferenciación para ser competitivos. Esta diferenciación puede obtenerse de varias formas: una, consiguiendo sellos o registros de empresa, los cuales pueden o pueden no repercutir en una mejora organizativa; o bien otra, con la obtención de buenos resultados empresariales, lo cual implica pensar antes de nada en la organización y en cómo debe esta gestionar sus actividades y recursos para alcanzar los objetivos planificados.

Es por tanto la intención orientar a empresas o futuros empresarios a pensar en la segunda opción, pensar en qué actividades son necesarias desarrollar y en cómo deben ser organizadas para alcanzar los resultados deseados. Además, para poder realizar dichas actividades se tendrá que pensar en los recursos necesarios y en las operaciones de control para evitar fallos previos a las entregas.

Si se analiza lo que se entiende por proceso en la norma [1] ISo 9000:2005 Vocabulario y terminología, vemos que es «el conjunto de actividades mutuamente relacionadas o que interactúan, las cuales transforman elementos de entrada en resultados».

Pero también, es necesario conocer que se entiende por procedimiento, para evitar confusiones futuras «la forma especificada para llevar a cabo una actividad o un proceso». Los procedimientos pueden estar documentados o no. Cuando un procedimiento está documentado, se utiliza con frecuencia el término procedimiento escrito o procedimiento documentado.

Si la intención de la empresa es analizar y mejorar sus procesos, eso significa que debe pensar en definir un sistema de gestión basado en procesos, para ello los modelos ISO 9001:2008 y el modelo EFQM tienen como principio básicos: «El enfoque por procesos».

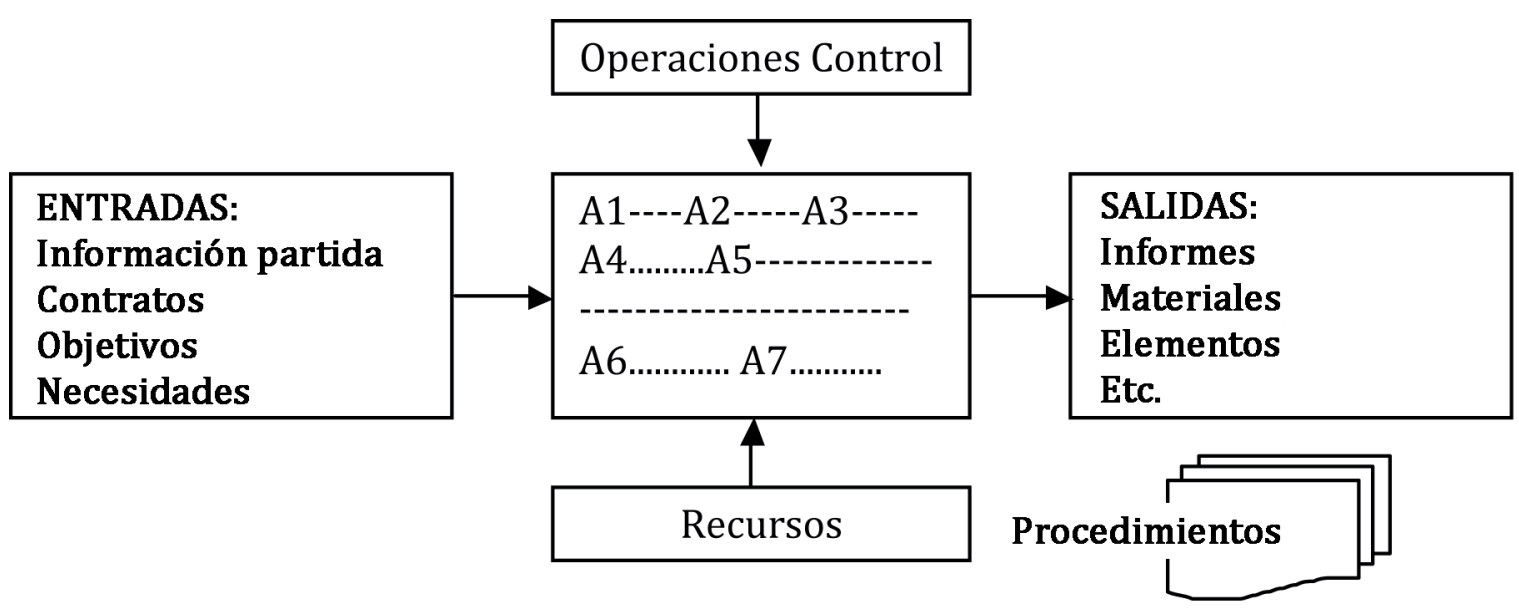

Figura 1: Esquema de un proceso genérico 
[4] El hecho de considerar las actividades agrupadas entre sí constituyendo procesos, permite a una organización centrar su atención sobre áreas de resultados (ya que los procesos deben obtener resultados), que es importante conocer y analizar para el control del conjunto de actividades y para conducir a la organización hacia la obtención de los resultados deseados.

Antes de iniciarnos en la materia, es recomendable tener presente que uno de los errores más frecuentes es plantear procesos mal identificados. Por ello es imprescindible identificar previamente los procesos, mediante el consenso de la Dirección, así como conocer las expectativas y necesidades de nuestros clientes. Posteriormente, analizaremos cuáles de los procesos repercuten directamente en la satisfacción del cliente. Se deben establecer y controlar objetivos medibles con respecto a cada uno de los procesos identificados y asegurarse de que los recursos técnicos adecuados para poderlos alcanzar se disponen.

\section{Gestión por procesos según las normas ISO 9001:2008}

[2] La ISO 9001:2008 promueve la adopción de un enfoque basado en procesos cuando se desarrolla, implementa y mejora la eficacia de un sistema de gestión de la calidad, para aumentar la satisfacción del cliente mediante el cumplimiento de sus requisitos. Según apartado 0.2 de la norma:

\section{2- Enfoque basado en procesos}

Para que una organización funcione de manera eficaz, tiene que determinar y gestionar numerosas actividades relacionadas entre sí. Una actividad o conjunto de actividades que utiliza recursos, y que se gestiona con el fin de permitir que los elementos de entrada se transformen en resultados, se puede considerar como un proceso. Frecuentemente el resultado de un proceso constituye directamente el elemento de entrada del siguiente proceso.

Se entiende que un enfoque por procesos es cuando una organización identifica, define la interacción y gestiona los procesos para producir el resultado deseado. Para cumplir con las exigencias de la norma, según su apartado 4.1- Requisitos generales, la empresa debe incluir en su manual de la calidad, el esquema o también llamado mapa de procesos, con el siguiente contenido como mínimo:

- los procesos identificados,

- la relación o relaciones existentes entre los mismos,

- y de manera opcional también los procedimientos que le son de aplicación. 


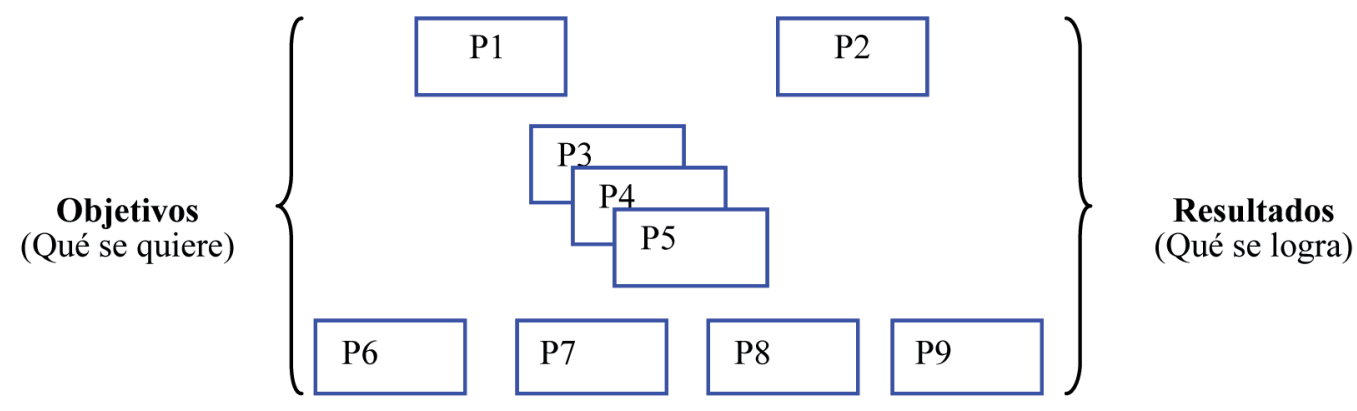

\section{Responsabilidades (Quién) \\ Recursos (Con qué) \\ Métodos (Cómo) \\ Programación (Cuándo)}

Figura 2: Sistema de gestión basado en procesos

Según la norma, se considera que:

0.2- Enfoque basado en procesos

Un enfoque de este tipo, cuando se utiliza dentro de un sistema de gestión de la calidad, enfatiza la importancia de:

a) la comprensión y el cumplimiento de los requisitos,

b) la necesidad de considerar los procesos en términos que aporten valor,

c) la obtención de resultados del desempeño y eficacia del proceso, y

d) la mejora continua de los procesos con base en mediciones objetivas. 


\section{Gestión por procesos según el modelo EFQM 2010}

[4] Las organizaciones que deseen ir más allá de la simple gestión de la calidad y traten de adoptar modelos de excelencia empresarial (ISO 9004 o modelo EFQM, respectivamente), deben reflexionar sobre este enfoque, porque se plantea como uno de los conceptos fundamentales de la excelencia en el modelo EFQM 2010, ver Figura 3:

La gestión por procesos en este caso tendrá que trasladarse de manera efectiva a su documentación que define el sistema de gestión, los procedimientos o metodologías y al control de sus actividades, personal, equipos, sin perder la idea de que todo ello debe servir para alcanzar los «resultados deseados».

$$
\begin{aligned}
& \text { Conceptos fundamentales de la excelencia: } \\
& \text { - Lograr resultados más equilibrados. } \\
& \text { - Añadir valor para los clientes. } \\
& \text { - Liderar con visión, inspiración e integridad. } \\
& \text { - Gestionar por procesos. } \\
& \text { - Alcanzar el éxito mediante las personas. } \\
& \text { - Favorecer la creatividad y la innovación. } \\
& \text { - Desarrollar alianzas. } \\
& \text { - Asumir responsabilidades de un futuro sostenible. }
\end{aligned}
$$

Gestionar por procesos, que en el nuevo modelo se entiende como «el diseño de los procesos» para realizar la estrategia, con una gestión de principio a fin más allá de los límites clásicos de la organización.

[6] Las recomendaciones que desde la Fundación Europea para la Gestión de la Calidad se presentan de cómo se pone en práctica este concepto aparecen en el siguiente cuadro: 
- Las organizaciones excelentes cuentan con un sistema de gestión eficaz y eficiente, basado en las necesidades y expectativas de todos los grupos de interés, y diseñado para satisfacerlas.

- Un conjunto de procesos claro e integrado hace posible y garantiza la implantación sistemática de las políticas, estrategias, objetivos y planes de la organización.

- Estos procesos se despliegan, gestionan y mejoran de forma eficaz en las actividades diarias de la organización.

- Las decisiones se basan en una información fiable y basada en datos de los resultados actuales y previstos, de la capacidad de los procesos y sistemas, las necesidades, expectativas y experiencias de los grupos de interés, y el rendimiento de otras organizaciones, incluido, cuando así conviene, el de la competencia.

- Se identifican los riesgos a partir de medidas de rendimiento sólidas, gestionándose de manera eficaz.

- La organización está gobernada con gran profesionalidad y alcanza, y excede, todos los requisitos que desde el exterior se le exigen.

- Se identifican e implantan las medidas preventivas adecuadas, inspirando y manteniendo altos niveles de confianza en los grupos de interés.

En definitiva, podemos decir que las recomendaciones así como el criterio 5: Procesos, Productos y Servicios revisado en el modelo EFQM 2010 coinciden con el enfoque basado en procesos para la norma ISO 9001:2008. 


\section{La definición de un sistema de gestión basado en procesos para el sector de la edificación}

Para definir un sistema de gestión basado en procesos podemos seguir las exigencias de la ISO 9001:2008, que en su apartado 4.1. nos indica:

\subsection{Requisitos generales}

La organización debe establecer, documentar, implantar y mantener un sistema de gestión de la calidad y mejorar continuamente su eficacia de acuerdo con los requisitos de esta norma internacional.

La organización debe:

a) Determinar los procesos necesarios para el sistema de gestión de la calidad y su aplicación a través de la organización.

b) Determinar la secuencia e interacción de estos procesos.

c) Determinar los criterios y los métodos necesarios para asegurarse de que tanto la operación como el control de estos procesos sean eficaces.

d) Asegurarse de la disponibilidad de recursos e información necesarios para apoyar la operación y el seguimiento de estos procesos.

e) Realizar el seguimiento, la medición cuando sea aplicable y el análisis de estos procesos.

f) Implementar las acciones necesarias para alcanzar los resultados planificados y la mejora continua de estos procesos.

En definitiva, lo que la norma exige a cualquier empresa del sector de la edificación que desee implantar gestión de la calidad es:

- Determinar o identificar los procesos necesarios.

- Definir la secuencia e interacción entre los procesos.

- Definir cómo realizar el seguimiento y mejora de los mismos para alcanzar los resultados esperados. 


\subsection{Determinación o identificación de los procesos necesarios en edificación}

Según exigencias de la norma Iso 9001:2008, el determinar los procesos implica identificar los estrictamente necesarios y describir las actividades o tareas que implican alcanzar los resultados esperados.

Si los procesos son grupos de actividades que dan como resultado un producto/ servicio, es una labor importante de la empresa definir qué procesos desarrolla la empresa.

La tendencia habitual es pensar que los procesos de la empresa son únicamente los que nos repercuten en beneficios económicos, dejando de lado aquellos que repercuten en beneficios estratégicos o bien beneficios en general para la organización.

Los procesos de una organización se pueden diferenciar en tres:

- procesos estratégicos o de gestión,

- procesos operativos o clave

- y los procesos de apoyo o soporte.

Los primeros, PE-procesos estratégicos, son aquellos que relacionan las actividades de dirección de la empresa, como podrían ser las actividades para la planificación a largo plazo y la revisión de las estrategias planificadas. Por ejemplo, «proceso de planificación empresarial». Los PC-procesos clave, son aquellos que dependen normalmente de la actividad productiva de la empresa, que están directamente relacionados con la realización del producto o servicio y que cuyos resultados nos revierten en beneficios económicos. Normalmente, su input/entrada es el contrato con un cliente y su resultado es un producto/servicio. Por ejemplo, si la empresa es constructora, «ejecución de vivienda», pero si la empresa es de tasación, «informes de tasación».

Los PA-procesos de apoyo son aquellos que ayudan al resto de procesos de una empresa. Un ejemplo; el «proceso de administración-contabilidad». Aunque estos procesos dependen del tipo de empresa y el nivel de subcontratación que tengan con alguna de estas actividades. Otros, por ejemplo, serán obligatorios si hay que implantar un sistema de gestión; como son los «procesos de gestión de calidad».

La identificación y descripción de los procesos puede ser labor ardua, pero aún se hace más difícil si no definimos un método para nombrar las actividades que se implican en cada uno de esos procesos. El método que propone la norma ISO 9001 para desarrollar el contenido de los procesos es seguir los siguientes pasos: Planificar-Hacer-Verificar-Actuar o también conocido por sus iniciales PHVA. Este modelo sirve de guía y simplifica la clasificación en cuatro actividades principales que siempre hay que realizar en un proceso para alcanzar un resultado. 
El número y la complejidad de los procesos siempre dependerán del tamaño y actividad de la organización.

Ejemplo de identificación de procesos para una empresa constructora de viviendas:

\begin{tabular}{|l|}
\hline Procesos estratégicos: \\
$\qquad \begin{array}{l}\text { P1-Planificación } \\
\text { P2-Revisión }\end{array}$ \\
\hline
\end{tabular}

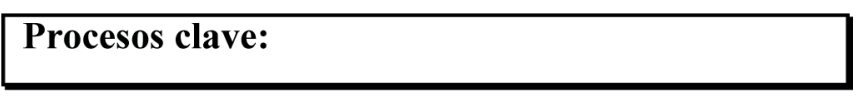

\begin{tabular}{|c|}
\hline $\begin{array}{l}\text { P3- Revisión del proyecto } \\
\text { P4- Compras } \\
\text { P5- Ejecución } \\
\text { P6- Servicio postventa }\end{array}$ \\
\hline os soporte: \\
\hline $\begin{array}{l}\text { P7- Personal } \\
\text { P8- Gestión } \\
\text { P9- Contabilidad }\end{array}$ \\
\hline
\end{tabular}

Empresa constructora

Figura 3: Ejemplo de identificación de procesos

La identificación de los procesos debe ser completada con la descripción de cada uno de ellos, para ello se puede generar una ficha modelo, en la cual cada proceso debe definir: las entradas, los resultados, las actividades, los procedimientos de aplicación en esas actividades, la capacitación profesional necesaria, los recursos técnicos necesarios, los controles internos, los indicadores de proceso, así como toda la información que la empresa considere oportuna para facilitar la implantación y seguimiento de los mismos. 
PROCEDIMIENTO No PR-11

Promocasa Algemesí S.L.

TÍTULO: DISEÑO Y DESARROLLO

\section{FICHA DE PROCESO}

\begin{tabular}{|c|c|c|}
\hline OBJETO & \multicolumn{2}{|c|}{$\begin{array}{l}\text { Este procedimiento establece el método por el que se garantiza la identificación } \\
\text { del Sistema de Gestión de Calidad en Promocasa Algemesí S.L. }\end{array}$} \\
\hline \multicolumn{3}{|c|}{ ALCANCE } \\
\hline \multicolumn{3}{|c|}{$\begin{array}{l}\text { Este Procedimiento afecta a todo Proyecto de edificación diseñado por el Departamento Técnico } \\
\text { de Promocasa Algemesí S. L. } \\
\text { El enciego del Diseño puede sr realizado por la promotora promocasa Algemesí S. L. ó bien por } \\
\text { otros promotores externos de la competencia, así como promotores particulares. }\end{array}$} \\
\hline \multicolumn{2}{|c|}{ ACTIVIDADES INICIALES } & ACTIVIDADES FINALES \\
\hline \multicolumn{2}{|c|}{ Entradas } & Salidas \\
\hline \multicolumn{2}{|c|}{ Resultdos del proceso de promoción } & Proyecto Básico \\
\hline \multicolumn{2}{|c|}{ Programa de necesidades del cliente/promotor } & Provecto de Eiecución \\
\hline \multicolumn{2}{|c|}{ Planos del solar / situación y entorno } & Estudio de seguridad y salud \\
\hline \multicolumn{2}{|c|}{ Tipo de construcción } & Control de calidad de la obra \\
\hline \multicolumn{2}{|l|}{ Normativa externa vigente } & Proyecto de telecomunicaciones \\
\hline \multicolumn{2}{|c|}{ Diseños exteriores y experiencia profesional } & Proyecto de ascensores \\
\hline \multicolumn{2}{|c|}{ Contribuciones de proveedores } & Proyecto de actividad de garajes \\
\hline \multicolumn{2}{|c|}{ Estudio geotécnico } & Liciencia de Primera Ocupación \\
\hline \multicolumn{2}{|c|}{ Proveedores } & Destinatarios \\
\hline \multicolumn{2}{|l|}{ Arquitectos } & Promotor \\
\hline \multicolumn{2}{|l|}{ Arquitecto Técnico } & Constructor \\
\hline \multicolumn{2}{|l|}{ Ingenieros } & Responsable de Ventas \\
\hline \multicolumn{3}{|c|}{ Ayuntamiento } \\
\hline \multicolumn{3}{|c|}{ Colegio Oficial Arquitectos y Arquitectos Técnicos } \\
\hline \multicolumn{3}{|c|}{ PERSONAL INVOLUCRADO } \\
\hline \multicolumn{2}{|c|}{ 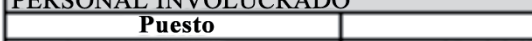 } & Implicación \\
\hline Arquitecto & \multicolumn{2}{|c|}{ Responsable del diseño, cálculo y memoria de los proyectos } \\
\hline Delineante & \multicolumn{2}{|c|}{ Delineación y Ploteado de los proyectos } \\
\hline Arquitecto Técnico & $\begin{array}{l}\text { Responsable del } \\
\text { Responsable del } \\
\text { Responsable del }\end{array}$ & Responsable del Control de Ejecución; y \\
\hline Promotor & Responsable de la & tación aportada \\
\hline Ingeniero de Teleco & Responsable del & Telecomunicaciones \\
\hline Ingeniero Industrial & Responsable de $\mathrm{P}$ & e Indicadores \\
\hline Responsable de Ventas & $\begin{array}{l}\text { Sugerencia y exp } \\
\text { como las modific }\end{array}$ & $\begin{array}{l}\text { e clientes de promocasa Algemesí S.L. Así } \\
\text { los puntos de venta iniciales. }\end{array}$ \\
\hline MEDIOS Y RECURSO & & \\
\hline $\begin{array}{l}\text { Los medios son: Diseño } \\
\text { grama informático AUTC } \\
\text { el programa CYPECAD } \\
\text { CIN. El ploteado de plan } \\
\text { doblado de plancha lo re } \\
\text { programa informático AI } \\
\text { color amarillo, las cuales }\end{array}$ & $\begin{array}{l}\text { de bocetos se hacen por } 1 \\
\text { CAD versión } 14 \text {. Cálcul } \\
\text { y la de la vivienda es pla } \\
\text { cha se realiza en la propi } \\
\text { liza el delineante. Los m } \\
\text { JTOPEM. La encuaderna } \\
\text { quedarán identificadas }\end{array}$ & $\begin{array}{l}\text { ura. Delineación por } 2 \text { delineantes con el pro- } \\
\text { uras de viviendas unifamiliares se realiza con } \\
\text { cálculo se realiza la empresa externa FORE- } \\
\text { n un Plotter y cortados por una guillotina. El } \\
\text { presupuesto de los proyectos se realizan con el } \\
\text { yectos la realiza el delinente en carpetas de } \\
\text { a que queda plasmado en la portada. }\end{array}$ \\
\hline CONTROLES & & \\
\hline Responsable & & Desripción \\
\hline Arquitecto & Control de Prove & \\
\hline O.C.T. & Control Técnico. I & verificador del proyecto, materiales y ejecución. \\
\hline Delineante & \begin{tabular}{|l} 
Control de Plano \\
\end{tabular} & \\
\hline Arquitecto Técnico & Control de Calida & ecto. \\
\hline A.Y.A.T. & Control Técnico & a de Calidades y Planos \\
\hline Director de la Calidad & $\begin{array}{l}\text { Coordinación de } \\
\text { proyecto y duran }\end{array}$ & $\begin{array}{l}\text { roveedores y subscripciones en la fase de } \\
\text { ión de obras. }\end{array}$ \\
\hline
\end{tabular}

Página 2 de 17

Figura 4: ficha del proceso de diseño cedido por la empresa Promocasa 


\subsection{Determinar la secuencia o interacción entre los procesos en edificación}

Según el concepto de proceso, sabemos que el resultado de un proceso puede ser la información de partida o la entrada de otro. Esto es lo que hace necesario determinar la secuencia entre los mismos para poder realmente definir el sistema de gestión.

Tras realizar previamente la identificación y descripción de los procesos, tendremos definidos los resultados que se obtienen de cada uno de ellos y se definirá a qué proceso precede.

La forma más sencilla de representar esta secuencia de procesos es por medio de un esquema, también llamado mapa de procesos; este tiene que contener: los procesos identificados por códigos o nombre y las líneas que identifican secuencia o continuidad. El esquema puede enriquecerse con una clasificación entre los procesos por medio de líneas o diferenciación de colores. Pero por otro lado, unos mapas de procesos excesivamente detallados pueden contener mucha información y por ello presentar dificultad en la interpretación de los procesos.

Los responsables de definir los procesos y su interacción siempre serán la dirección de la empresa en colaboración el director de gestión.

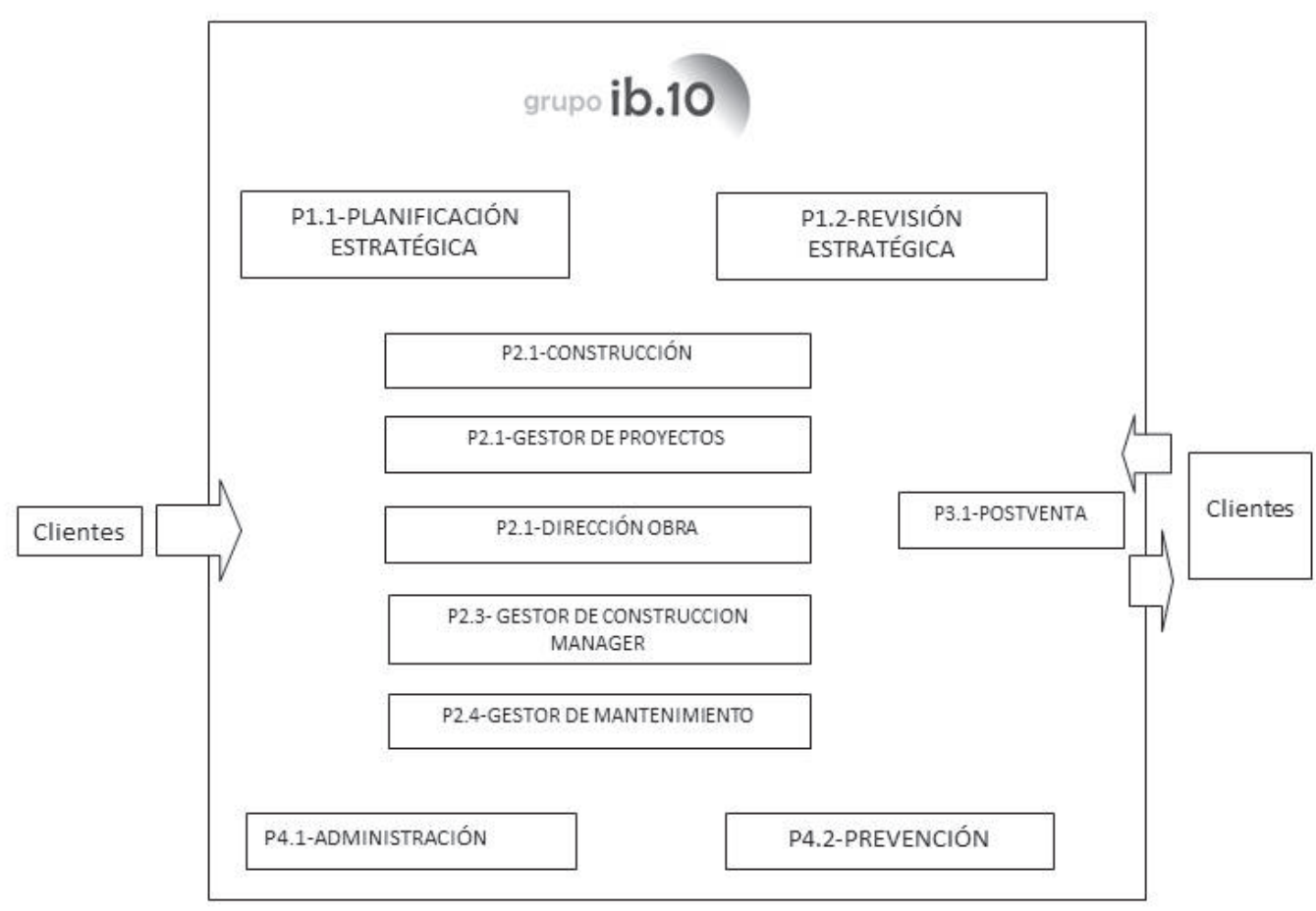

Figura 5: Mapa de procesos propuesto por Juan Climent para MAYPE 


\subsection{Seguimiento de los procesos}

La definición de un mapa de procesos en la organización ayuda a analizar de manera seccionada un conjunto de actividades, sobre todo aquellas que repercuten en los resultados. La aplicación del modelo PHVA, asegura la implantación de la mejora continua. El modelo sirve como método para realizar el seguimiento de la eficacia de cada proceso.

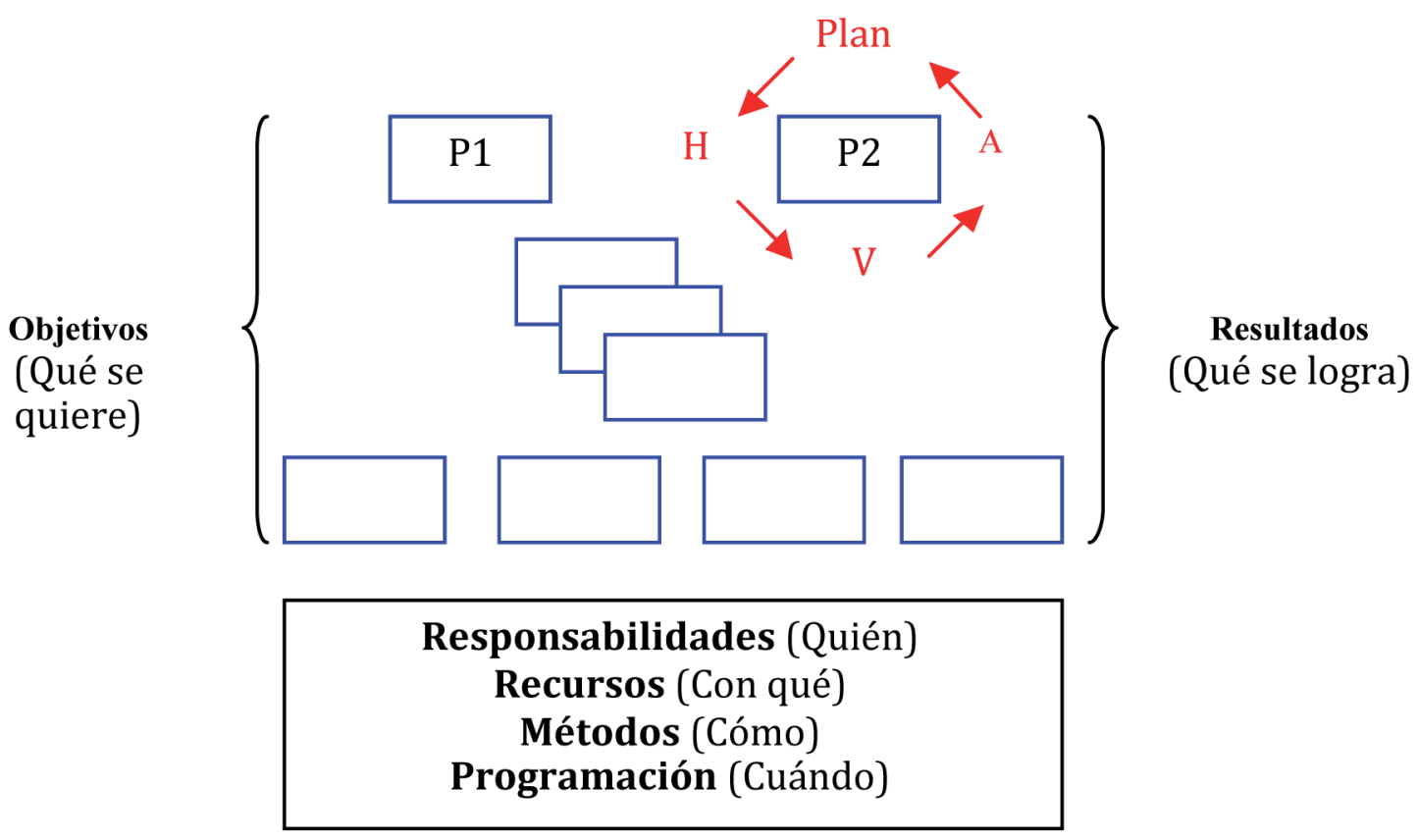

Figura 6: Sistema de gestión basado en procesos orientado a la mejora continua

Por ello en cada proceso deberemos:

- planificar unos criterios de eficacia del proceso,

- realizar el seguimiento periódicamente para detectar desviaciones,

- analizar los resultados,

- proponer acciones de mejora.

Una organización debería preocuparse por alcanzar los resultados deseados optimizando el uso de recursos, además de [1] la eficacia, debería considerar la eficiencia en los procesos. Esto es indispensable si se desea la excelencia empresarial (ISO 9004:2009 y/o modelo EFQM 2010).

Para realizar por tanto el seguimiento, se definirán los parámetros de medida o también llamados indicadores, estos son ratios (valores adimensionales) que proporcionan datos como un resultado de la medición de un proceso. Podemos encontrar indicadores de eficacia y de eficiencia. Los indicadores de eficacia están relacionados con los ratios que nos indican capacidad o acierto en la consecución de tareas y/o trabajos, como por ejemplo el grado de satisfacción de los clientes con relación a los pedidos. Mientras que los indicadores de eficiencia están relacionados con los 
ratios que nos indican el tiempo invertido en la consecución de tareas y/o trabajos (si tenemos en cuenta que eficiencia tiene que ver con la actitud y la capacidad para llevar a cabo un trabajo o una tarea con el mínimo gasto de tiempo), un ejemplo; el tiempo de fabricación de un determinado producto, etc.

Los indicadores permiten establecer, en un proceso o conjunto de procesos, aquello que es necesario medir para conocer la eficacia del mismo. En el caso de tener interés por conocer la eficiencia del proceso se debería tener en consideración los recursos que se consumen (tiempo, horas/personal, coste).

Para establecer el seguimiento de los procesos a partir de indicadores se recomienda [4]:

$1 .^{\circ}$ Reflexionar sobre la misión del proceso.

$2 .^{\circ}$ Determinar la tipología de resultados a obtener y las magnitudes (por ejemplo, $\%$ a medir.

3. ${ }^{\circ}$ Determinar los indicadores representativos de las magnitudes a medir.

4. ${ }^{\circ}$ Establecer los resultados que se desea alcanzar para cada indicador definido.

$5 .^{\circ}$ Formalizar los indicadores con los resultados que se desea alcanzar (objetivos).

A modo de ejemplo para una empresa que desarrolle proyectos arquitectónicos:

$1 .^{\circ}$ La misión del proceso de proyectos, que sean capaces de definir las especificaciones técnicas y administrativas para ejecutar un edificio.

$2 .^{\circ}$ Resultados: errores de proyecto, plazo de entrega de proyecto.

$3 .^{\circ}$ Indicadores:

Indicador 1-PP: (N. ${ }^{\circ}$ errores de cálculo/N. ${ }^{\circ}$ errores detectados por otros agentes) $\%$

Indicador 2-PP: (Días reales hasta la entrega/Días estimados de entrega) \%

4. ${ }^{\text {E }}$ Establecer comparativa: Criterios/Objetivos:

Indicador 1-Pp (Objetivo: $5 \%$ de todos los proyectos anuales)

Indicador 2-PP (Objetivo: 10\% de retrasos en los proyectos anuales)

5. ${ }^{\circ}$ Formalizar los indicadores con los resultados:

Indicador 1-PP (Resultados durante 12 meses. Se representarían los resultados obtenidos comparando todos los proyectos realizados en ese año y se calcularía la media.

\begin{tabular}{|c|c|c|c|c|}
\hline Indicador & Unidad med. & Fuentes inf. & Periodo & Objetivo \\
\hline Errores P & $\%$ & Modificaciones P & Ejecución obra & No superar el 5\% \\
\hline
\end{tabular}




\section{Referencias}

[1] UNE EN-ISO 9000: 2005. Sistemas de gestión de la calidad, fundamentos y vocabulario. AENOR.

[2] UNE EN-ISO 9001: 2008. Requisitos para la gestión de la calidad. AENOR.

[3] UNE EN-ISO 9004: 2009. Gestión para el éxito sostenido de una organización. Enfoque de gestión de la calidad. AENOR.

[4] Guía para una gestión basada en procesos. Jaime Beltrán Sanz, Miguel A. Carmona Calvo, Remigio Carrasco Pérez, Miguel A. Rivas Zapata, Fernando Tejedor Panchón. 2002. Instituto Andaluz de Tecnología.

[5] Gestión de la calidad en la arquitectura técnica. Coord. Antonio Garrido y Eduardo Montero. Consejo General de la Arquitectura Técnica de España. 2008.

[6] Guía modelo EFQM. Fundación europea para la Gestión de la Calidad. 2002.

[7] Guía de transición al modelo EFQM. Paul Gemoets. 2009.

\section{Webs}

[8] Gestión-Calidad Consulting http://www.gestion-calidad.com/gestion-procesos.html

[9] El Instituto para la Calidad de las ONG-ICONG http://www.ongconcalidad.org/ gprocesos.pdf 


\section{TEMA 4}

\section{Gestión de los documentos}

1. Mapa de conceptos

2. Competencias

3. Objetivos

4. Introducción

5. Contenido

5.1. Referencia a norma

5.2. Referencia a la legislación vigente para el sector de la edificación

5.3. Identificación y contenido de los documentos del sistema de gestión

5.4. Herramientas para la gestión documental

6. Referencias

7. Webs 


\section{Mapa de conceptos}

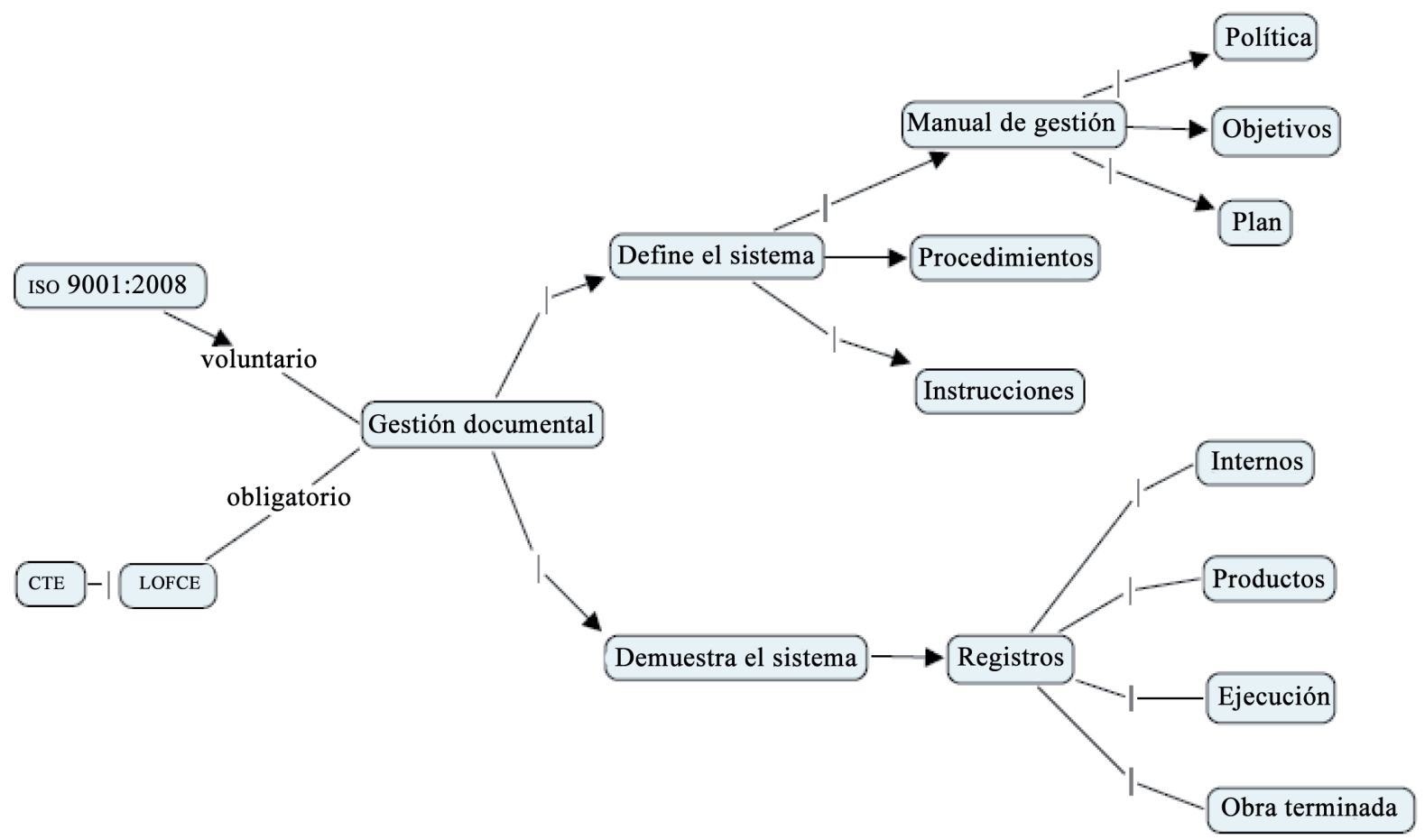

\section{Competencias ${ }^{1}$}

ME18. Conocer la legislación, reglamentación y normativas específicas en los procesos de edificación.

OP18. Gestionar las nuevas tecnologías edificatorias y participar en los procesos de gestión de la calidad en la edificación.

\section{Objetivos}

Identificar las exigencias desde la normativa que nos obligan a cumplir con el control de los documentos.

1. La descripción de estas competencias ha sido concretada para el tema en cuestión. 
Conocer qué documentos son necesarios para definir un sistema de gestión de la organización.

Saber qué son los registros y cómo se documentan.

Aprender cómo se pueden controlar todos los documentos que definen y demuestran la gestión de la organización.

\section{Introducción}

Uno de los aspectos más criticados de la gestión empresarial respecto a las normas de referencia es la burocracia que genera el uso y mantenimiento de la documentación. Este problema es debido a la necesidad que tienen las empresas de tener que demostrar el cumplimiento de la norma o bien su implantación ante segundas partes (cliente) o terceras partes (entidades de certificación).

Si analizamos las exigencias de las normas de gestión, comprobaremos tres cosas que tenemos que tener en cuenta previo a la definición del sistema: 1) que los documentos a gestionar deben ser evidencias del cumplimiento de la norma; 2) que el volumen de documentación depende de las necesidades de la empresa y no de las normas; 3) que no se tiene calidad en una organización si no se cumple con las obligaciones legales que le son de aplicación a la empresa o a la actividad que esta desarrolla. Por tanto, se recomienda que previo a la definición del sistema se analice la documentación que es obligatoria por la legislación vigente y la norma o normas de gestión de referencia.

Respecto a la legislación vigente, en nuestro caso particular para el sector de la construcción y concretamente para el sector de la edificación en la Comunidad Valenciana, se deberá cumplir con las exigencias legales respecto a la documentación del Código Técnico (СTE), la Ley para el fomento de la calidad de la Comunidad Valenciana (LOFCE) y el Libro de control de la calidad en edificación (LC91), actualmente en revisión.

Respecto a las normas de gestión de la calidad, si tomamos como referencia la UNE EN-ISO 9001:2008 se deberá cumplir con los requisitos de la documentación definidos en su apartado 4. Así como si tomamos como referencia la norma para la gestión del conocimiento que nos exige la necesidad de almacenar y administrar el conocimiento, lo cual implica en muchos casos la necesidad de generar documentación que se pueda almacenar y administrar; en definitiva, es necesario definir sistemas de gestión de los documentos. 


\section{Contenido}

\subsection{Referencia a norma}

\subsubsection{ISO 9001:2008 Requisitos para la gestión de la calidad}

En su apartado 4.2 Requisitos de la documentación, la norma ISO 9001:2008 indica que la documentación que debe incluir un sistema de gestión de la calidad es:

a) Declaraciones documentadas de una política de la calidad y de objetivos de la calidad.

b) Un manual de la calidad.

c) Los procedimientos documentados y los registros requeridos por esta norma internacional.

d) Los documentos, incluidos los registros que la organización determina que son necesarios para asegurarse la eficaz planificación, operación y control de sus procesos.

Nota 1. Cuando aparece el término «procedimiento documentado» dentro de esta norma internacional significa que el procedimiento sea establecido, documentado, implementado y mantenido. Un solo documento puede incluir los requisitos para uno o más procedimientos. Un requisito relativo a un procedimiento documentado puede cubrirse con más de un documento.

Nota 2. La extensión de la documentación del sistema de gestión de la calidad puede diferir de una organización a otra debido a: el tamaño de la organización y el tipo de actividades; la complejidad de los procesos y sus interacciones; y la competencia del personal.

Nota 3. La documentación puede estar en cualquier formato o tipo de medio.

\subsubsection{Gestión del conocimiento}

Las actividades básicas de la GC están relacionadas a diferentes campos del saber. Los especialistas en estos temas definen varias actividades que integran el «ciclo de vida del conocimiento» o la «cadena del valor del conocimiento»; siendo las más generales las destinadas a identificar, crear, almacenar, compartir y utilizar el conocimiento.

La actividad para almacenar el conocimiento se considera como algo significativo en la construcción de activos de conocimiento, puesto que el conocimiento debe incorporarse a la organización para facilitar su re-utilización. Adquiere 
mayor relevancia en organizaciones donde existen pocos especialistas en diferentes temas de importancia, cuya pérdida podría ser negativa en caso de que se retiren o decidan abandonar la organización por cualquier motivo. Este efecto se atenuará en gran medida si la organización fue capaz de almacenar el conocimiento (procedimientos, manuales, mejores prácticas, sugerencias a proyectos ejecutados, etc.) de esos expertos, facilitándose su transferencia a otros.

En su etapa 3-Desarrollo se definen algunas herramientas a modo de ejemplo que pueden ser utilizadas en la actividad para almacenar el conocimiento:

- Bases de datos.

- Sistemas de gestión de documentos.

- Bases de datos de empleados (conocimientos, formación, experiencias, etc.).

- Páginas amarillas.

- Data Warehouse.

- Sistemas expertos.

- Literatura especializada.

- Manuales.

La información que las personas necesitan para su trabajo diario se encuentra generalmente en documentos u otros objetos (gráficos, fotografías, vídeos). La administración de documentos trata de proveer soluciones para procesar, almacenar, cambiar, administrar, buscar y borrar documentos. Es de suma importancia tener disponibles de forma más eficiente la información y el conocimiento contenido en documentos para que puedan ser consultados con el mínimo esfuerzo.

\subsection{Referencia a la legislación vigente para el sector de la edificación}

La legislación referente a exigencias técnicas y de calidad en el sector de la edificación es muy amplia, tanto que se debe cumplir con la legislación europea, nacional, de la comunidad e incluso del propio municipio. En este apartado se recogen las exigencias respecto a la documentación en la legislación nacional y de la Comunidad Valenciana.

\subsubsection{Código técnico (СТЕ)}

En los siguientes capítulos del CTE se obliga a gestionar los documentos que serán necesarios para demostrar el cumplimiento de su desarrollo en la ejecución de las obras.

Cap. 2 (art. 7)- Condiciones en la ejecución de las obras

7.2. Control de recepción en obra de productos, equipos y sistemas 
El control de recepción tiene por objeto comprobar que las características técnicas de los productos, equipos y sistemas suministrados satisfacen lo exigido en el proyecto. Este control comprenderá:

a) El control de la documentación de los suministros, realizado de acuerdo con el artículo 7.2.1; que consiste en:

- los documentos de origen, hoja de suministro y etiquetado;

- el certificado de garantía del fabricante, firmado por persona física; y

- los documentos de conformidad o autorizaciones administrativas exigidas reglamentariamente, incluida la documentación correspondiente al marcado CE de los productos de construcción.

b) El control mediante distintivos de calidad o evaluaciones técnicas de idoneidad, según el artículo 7.2.2.

El suministrador proporcionará la documentación precisa y el director de la ejecución de la obra verificará que esta documentación es suficiente para la aceptación de los productos, equipos y sistemas amparados por ella.

c) El control mediante ensayos, conforme al artículo 7.2.3.

Para verificar el cumplimiento de las exigencias básicas del CTE puede ser necesario, en determinados casos, realizar ensayos y pruebas sobre algunos productos, según lo establecido en la reglamentación vigente, o bien según lo especificado en el proyecto u ordenado por la dirección facultativa.

\subsection{Control de ejecución de la obra}

Durante la construcción, el director de la ejecución de la obra controlará las certificaciones de conformidad que ostenten los agentes que intervienen, así como las verificaciones que, en su caso, realicen las entidades de control de calidad de la edificación.

Se adoptarán los métodos y procedimientos que se contemplen en las evaluaciones técnicas de idoneidad en el caso de sistemas innovadores.

Cap. 2 (art. 8)- Condiciones del edificio

\subsection{Documentación de la obra ejecutada}

- Se incluirá en el libro del edificio la documentación indicada en el artículo 7.2 de los productos, equipos y sistemas que se incorporen a la obra.

Anexo II. Documentación del seguimiento de la obra.

En este anexo se detalla, con carácter indicativo y sin perjuicio de lo que establezcan otras administraciones públicas competentes, el contenido de la documentación del 
seguimiento de la ejecución de la obra, tanto la exigida reglamentariamente, como la documentación del control realizado a lo largo de la obra.

II.1. Documentación obligatoria del seguimiento de la obra:

- el libro de órdenes y asistencias;

- el libro de incidencias en materia de seguridad y salud;

- el proyecto, sus anexos y modificaciones debidamente autorizados por el director de obra;

- la licencia de obras, la apertura del centro de trabajo y, en su caso, otras autorizaciones administrativas; $y$

- el certificado final de la obra.

II.2. Documentación del control de la obra:

- el director de la ejecución de la obra recopilará la documentación del control realizado, verificando que es conforme con lo establecido en el proyecto, sus anexos y modificaciones;

- el constructor recabará de los suministradores de productos y facilitará al director de obra y al director de la ejecución de la obra la documentación de los productos anteriormente señalada así como sus instrucciones de uso y mantenimiento, y las garantías correspondientes cuando proceda; y

- la documentación de calidad preparada por el constructor sobre cada una de las unidades de obra podrá servir, si así lo autorizara el director de la ejecución de la obra, como parte del control de calidad de la obra.

Una vez finalizada la obra, la documentación del seguimiento del control será depositada por el director de la ejecución de la obra en el colegio profesional correspondiente $\mathrm{o}$, en su caso, en la administración pública competente, que asegure su tutela y se comprometa a emitir certificaciones de su contenido a quienes acrediten un interés legítimo.

II.1. Certificado final de obra:

- en el certificado final de obra, el director de la ejecución de la obra certificará haber dirigido la ejecución material y controlado cuantitativa y cualitativamente la construcción y la calidad de lo edificado de acuerdo con el proyecto, la documentación técnica que lo desarrolla y las normas de la buena construcción.

II.2. Al certificado final de obra se le unirán como anexos los siguientes documentos:

- descripción de las modificaciones.

- relación de los controles realizados durante la ejecución de la obra y sus resultados.

\subsubsection{Ley de fomento de la calidad de la edificación (LOFCE)}

En su Capítulo 1. Sección 3.a: La ejecución de las obras. Artículo 13: Generalidades. Durante la ejecución de las obras, se reseñarán las actuaciones habidas en ella, mediante los siguientes documentos: 
- Libro de órdenes y asistencias: es el documento en donde se reflejan las actuaciones relevantes en la obra y sus hitos, junto con las instrucciones, modificaciones, órdenes u otras informaciones dirigidas al constructor por la dirección facultativa de la obra.

- Libro de gestión de calidad de obra: es el documento en el que se refleja la información objetiva de cómo se ha realizado la gestión de calidad, así como los resultados de las actuaciones de los diversos agentes intervinientes en la misma. Según el modelo y procedimiento que la Generalitat determine. (Documento futuro.)

Ambos documentos se desarrollarán reglamentariamente y pueden, para determinado tipo de obras, refundirse en uno solo.

\subsubsection{Libro de control de calidad (LC91)}

La aplicación de la LC91 en obras de edificación implica realizar:

- La justificación del control (impresos 1 y 2).

- La evaluación de riesgos (impreso 3).

- La programación del control de los materiales (impresos 4, 5, 6, 7, 8, 9, 10) y de la ejecución (impresos 11, 13 y 14).

\subsection{Identificación y contenido de los documentos del sistema de gestión}

Los documentos que hay que gestionar en una empresa que quiera implantar un sistema de gestión serán: los documentos que definen el SG y los documentos que demuestran el cumplimiento del SG.

\subsubsection{Documentos que definen el SG}

Como es tan grande la cantidad de documentos a gestionar, lo primero que se recomienda según la ISO 9001:2008 para el control de los documentos es redactar un procedimiento documentado que defina cómo se elaboran y se identifican los documentos, cómo se aprueban, cómo se distribuyen, cómo se revisan y actualizan y cómo se archivan.

a) Elaboración e identificación de los documentos

En primer lugar, se recomienda definir el sistema de identificación o también llamado codificación de documentos que se van a generar. En este caso el sistema de codificación propuesto es de aplicación a los documentos que definen el sistema, 
aunque fácilmente este mismo se podría extrapolar a los documentos que demuestran el sistema o también llamados registros. En el caso de codificar registros, tan solo se tendría que realizar un esfuerzo de identificación de todos los documentos que evidencian el cumplimiento de las normas, bien sean documentos internos o documentos externos.

Los documentos internos son registros que resultan del uso y aplicación de un formato de un procedimiento para un proyecto u obra concreta. Los documentos externos serían registros que son evidencias del cumplimiento de ese procedimiento pero que no han sido elaborados por nosotros, por ejemplo: albaranes de la obra, distintivos de la calidad o medioambientales, los documentos de proyecto, etc.

Hay que recordar que esta codificación debe ser acordada para toda la empresa, que debe ser sencilla y que debe incluir referencia al tipo de documento, al orden de elaboración. En algunos casos también se puede recomendar que haga referencia al proceso donde es de aplicación, referencia a la versión. Aún así recordemos la importancia de la simplificación y sencillez del sistema, porque será utilizado por todos los trabajadores de la empresa.

En la biografía se han encontrado referencias a sistemas de codificación para empresas de direcciones técnicas [6]. En el que se relacionan con una matriz los procesos y actividades. En este documento vamos a pretender un sistema de codificación más sencillo, cuyos códigos contienen:

\begin{tabular}{|c|c|c|c|}
\hline Tipo de documento & Orden de edición & Versión edición & Título \\
\hline MG & 001 & -00 & Manual de gestión \\
\hline P & 001 & -00 & Procedimiento de diseño \\
\hline I & 001 & -00 & Instrucción de diseño \\
\hline F & 001 & -00 & Formato de diseño \\
\hline
\end{tabular}

Figura 1: Esquema para la codificación de documentos

Además de este código, en cada documento siempre se identificará la fecha de su edición y como mínimo fecha de aprobación, así como firma de quién lo edita y quién lo aprueba.

Como hemos comentado anteriormente, este código siempre se podría complementar incluyendo alguna sigla que haga referencia al proceso para el cual será de aplicación, esto solo sería para los procedimientos, las instrucciones y los formatos.

\begin{tabular}{|c|c|c|c|c|}
\hline Tipo de documento & Proceso & Orden de edición & Versión edición & Título \\
\hline P & D & 001 & -00 & Procedimiento de diseño \\
\hline I & D & 001 & -00 & Instrucción de diseño \\
\hline F & D & 001 & -00 & Formato de diseño \\
\hline
\end{tabular}

Figura 2: Esquema para la codificación de documentos con referencia a procesos 
Esta última propuesta podría ser más completa y demostraría el enfoque a procesos que solicita la norma.

Como ya se ha dicho en temas anteriores, un sistema de gestión es particular de cada empresa, por lo que este tema se debe entender como una recomendación de contenidos de los documentos del SG, perfectamente la empresa podrá elegir entre formas de documentos más desarrollados o formas de documentos más esquemáticos. Lo que no podemos obviar es el contenido mínimo de los mismos.

Según la norma ISO 9001 los documentos que definen un sistema de gestión son el manual de gestión de la calidad, los procedimientos y las instrucciones. A continuación se propone el contenido mínimo del MG así como el índice y forma de los procedimientos e instrucciones.

a) Forma y contenido del Manual de Gestión (MG) [8]

La forma del MG será elaborada y aprobada por la empresa, normalmente son funciones que recaen en el director de gestión la elaboración y en la dirección de la empresa.

Por su contenido podemos tener dos formas de orientarlo, bien a un contenido principalmente orientado a procesos o bien un contenido orientado a la norma $\mathrm{u}$ normas de referencia. Cualquiera de ellos es válido, lo más importante es que sean documentos entendidos por todos.

Recordemos que un manual puede ser un documento público para clientes o partes interesadas de la empresa, no contiene la operativa o formas de actuar de la empresa, tan solo debe contener el «qué» se hace en nuestra empresa para implantar gestión integral.

\section{1- La portada.}

La portada de todo documento debe informar del contenido del mismo, por tanto se recomienda que identifique para qué empresa será de aplicación, esta información puede ser el propio logo de la empresa ubicado en el encabezamiento o bien el nombre completo de la empresa. Deberá incluir el código del documento en este caso particular MG001-00, ubicado en el mismo encabezamiento, margen derecho, dejando en el centro del encabezamiento espacio para hacer referencia al nombre o nombre del documento simplificado; por ejemplo, Manual de Gestión. En el centro de la portada, se puede hacer referencia al nombre del documento completo; por ejemplo, Manual de Gestión Integral. En la parte inferior del documento es importante hacer referencia a quién ha elaborado el documento, quién lo ha aprobado, con fecha y firma. En el caso de realizar tres actividades como podrían ser: elaboración, aprobación y validación, porque son tres responsables diferentes, se debería dejar espacio reservado para la fecha y firma de las tres personas. Como recomendación, cuantas más personas estén implicadas en la firma y puesta en marcha o implantación de un documento más burocracia se hará en la empresa. 
No nos deberíamos olvidar de hacer referencia también a las páginas que contiene el documento, en este caso particular el MG es indivisible, por lo que con decir en la página que nos encontramos sería suficiente, pero como recomendación sería preferible paginar indicando página respecto de un total. Por ejemplo, en el caso de ser la portada $1 / 50$.

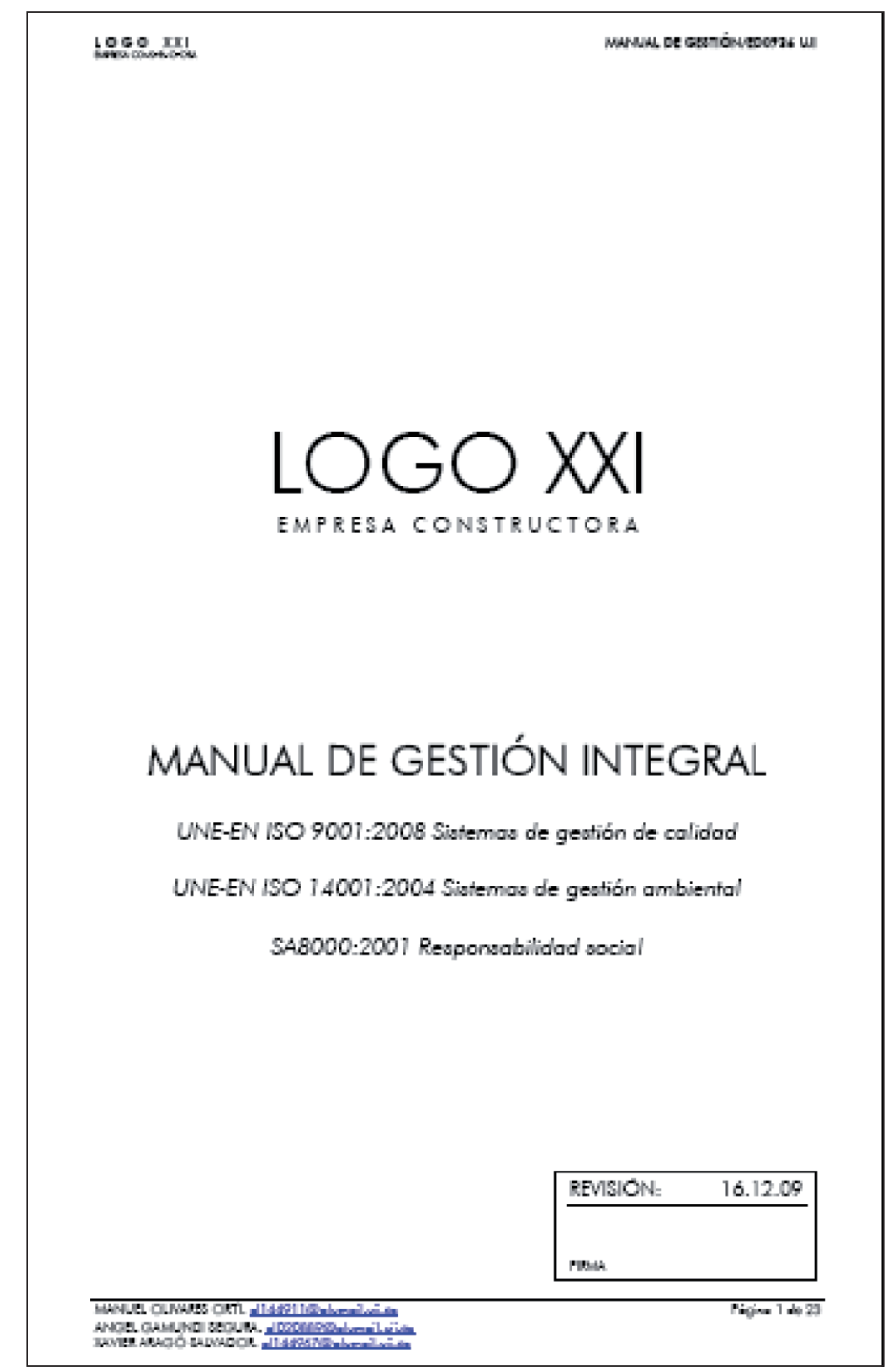

Figura 3: Portada del manual de gestión integral

El contenido real del documento se definirá desde el índice. El contenido puede estar basado en la norma o normas de referencia o bien en procesos:

1- Índice según los requisitos de las normas:

A-Información o introducción sobre la empresa. Es bastante normal que una empresa previo a la implantación del sistema de gestión tenga una historia, una evolución en su trabajo, por ello se considera de interés el poder informar de las características propias de la empresa donde se indicará principalmente de los servicios que ofrece, de los clientes con quienes contrata, etc. 
B-Ámbito de aplicación del MG. Se deberá definir concretamente si se aplica a la totalidad de las actividades de una empresa o bien si se aplica de manera parcial.

C- Organización. Se deberá definir con un organigrama la relación funcional y de responsabilidades que existe entre los distintos puestos de la empresa. En este apartado también se recomienda la descripción de cada puesto de trabajo indicando las competencias que se le requieren y las funciones que dentro de la empresa deberá desempeñar.

D- Identificación y relación entre procesos. En este apartado se deben definir los procesos de la empresa y como estos se relacionan, recordemos que en muchos de los casos el resultado de un proceso es la entrada de otro proceso. Por esta razón se debe incluir con lo que se conoce como mapa de procesos. Será o puede ser en este apartado donde se haga referencia si se puede, a posibles exclusiones del proceso de Diseño, es el único que permite la norma ISO 9001:2008.

E- Generalidades de la documentación. Es en este apartado se debe detallar la codificación de los documentos del sistema, se deben identificar los documentos que definen el sistema, indicar el soporte de los documentos e incluso el periodo de archivo de los mismos. Si lo considerara de interés la empresa, también se podría hacer referencia a algún procedimiento para la redacción de procedimientos e instrucciones.

F- Política de empresa. Este documento exige todas las normas de gestión; en este documento se recopilan los compromisos de la empresa y concretamente de la dirección para el cumplir con los principios y requisitos de las normas. No se recomienda gran extensión siendo un documento de intenciones que debe estar firmado por la dirección de la empresa. Según las normas, esta política debe ser conocida por toda la empresa.

G-Planificación. En este apartado se deberán definir los objetivos para alcanzar la política previamente publicada y comunicada. Objetivos que deben ser concretos y medibles. Objetivos que podrán ser para la implantación del sistema, económicos, productivos, etc. En cualquier caso la planificación de objetivos podría ser una actividad repetida proyecto a proyecto, obra a obra o bien anualmente; por tanto, se podría hacer referencia al procedimiento concreto, el cual implantaría la Dirección o los responsables de procesos o departamentos de la empresa.

H-Realización de productos o servicios. En este apartado se definirían los procedimientos documentados o no que harían falta para desarrollar los procesos clave, previamente identificados.

I- Seguimiento, medición y mejora. En esta apartado la empresa debe indicar qué hará para realizar el seguimiento, la medición y las mejoras del sistema y de la producción de la empresa. En este caso se recomienda hacer referencia como mínimo a los procedimientos documentados que exige la norma Iso 9001:2008 y que le son de aplicación. 
$J$ - Control de cambios. Este apartado no es una exigencia de la norma, pero puede ser de utilidad para conocer las versiones y con ello la evolución del MG.

K-Anexos. El primer anexo recomendado sería el «Listado de procedimientos», esta información puede ser de interés para futuras revisiones del MG y para que aun siendo un documento externo del MG pueda ir actualizándose según se creen y aprueben procedimientos en la empresa.

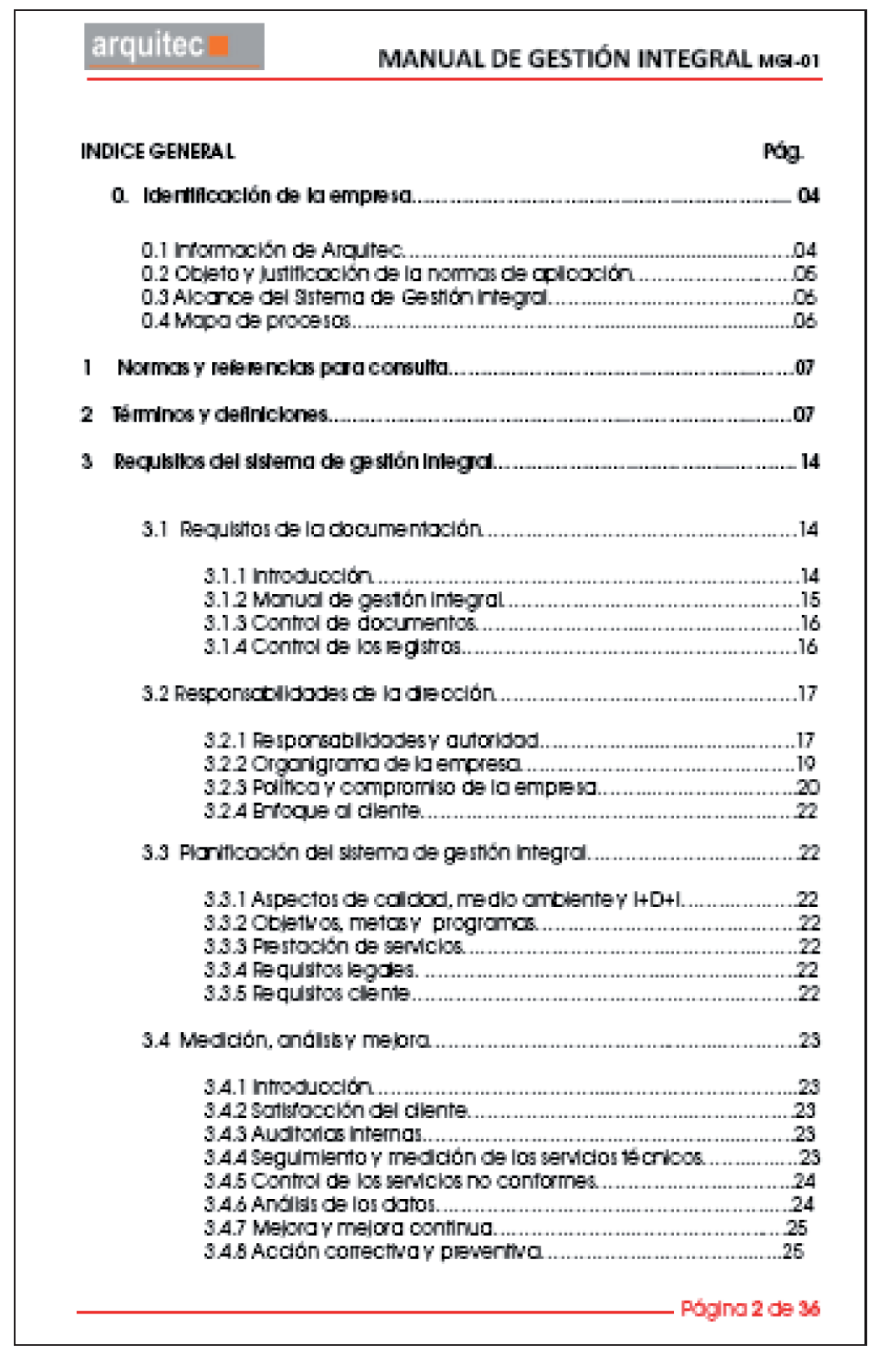

Figura 4: Índice del manual de gestión integral según normas

2- Índice según procesos de la empresa:

A-Información o introducción sobre la empresa. Es bastante normal que una empresa previo a la implantación del sistema de gestión tenga una historia, una evolución en su trabajo, por ello se considera de interés el poder informar de las características propias de la empresa donde se indicará principalmente de los servicios que ofrece, de los clientes con quienes contrata, etc.

$B$ - Ámbito de aplicación del MG. Se deberá definir concretamente si se aplica a la totalidad de las actividades de una empresa o bien si se aplica de manera parcial. 
C- Organización. Se deberá definir con un organigrama la relación funcional y de responsabilidades que existe entre los distintos puestos de la empresa. En este apartado también se recomienda la descripción de cada puesto de trabajo indicando las competencias que se le requieren y las funciones que dentro de la empresa deberá desempeñar.

D- Generalidades de la documentación. Es en este apartado donde se debe detallar el sistema de codificación de los documentos que definen el sistema, se deben identificar los documentos que definen el sistema, indicar el soporte de los documentos e incluso el periodo de archivo de los mismos. Si lo considerara de interés la empresa, también se podría hacer referencia a algún procedimiento para la redacción de procedimientos e instrucciones.

E- Política de empresa. Este documento exige todas las normas de gestión; en este documento se recopilan los compromisos de la empresa y concretamente de la dirección para el cumplir con los principios y requisitos de las normas. No se recomienda gran extensión siendo un documento de intenciones que debe estar firmado por la dirección de la empresa. Según las normas, esta política debe ser conocida por toda la empresa.

F- Identificación y relación entre procesos. En este apartado se deben definir los procesos de la empresa y como estos se relacionan, recordemos que en muchos de los casos el resultado de un proceso es la entrada de otro proceso. Por esta razón se debe incluir con lo que se conoce como mapa de procesos. Será o puede ser en este apartado donde se haga referencia, si se puede, a posibles exclusiones del proceso de diseño; es el único que permite la norma ISO 9001:2008.

F1-Procesos estratégicos. Siguiendo la relación de procesos estratégicos definidos en el apartado anterior, en este apartado se incluye la ficha de cada proceso, fichas que nos indican qué se hace en dicho proceso y qué procedimientos le son de aplicación.

F2- Procesos clave. Siguiendo la relación de procesos clave definidos anteriormente, en este apartado se incluye la ficha de cada proceso, fichas que nos indican qué se hace en dicho proceso y se hace referencia a los procedimientos que son de aplicación.

F3- Procesos de apoyo. Siguiendo la relación de procesos soporte o apoyo, definidos en el apartado anterior, en este apartado se incluye la ficha de cada proceso, fichas que nos indica qué se hace en el proceso y se hace referencia a los procedimientos que le son de aplicación.

$G$ - Control de cambios. Este apartado no es una exigencia de la norma, pero puede ser de utilidad para conocer las versiones y con ello la evolución del MG.

H-Anexos. El primer anexo recomendado sería el «Listado de procedimientos», esta información puede ser de interés para futuras revisiones del MG y para que 
aun siendo un documento externo del MG pueda ir actualizándose según se creen y aprueben procedimientos en la empresa.

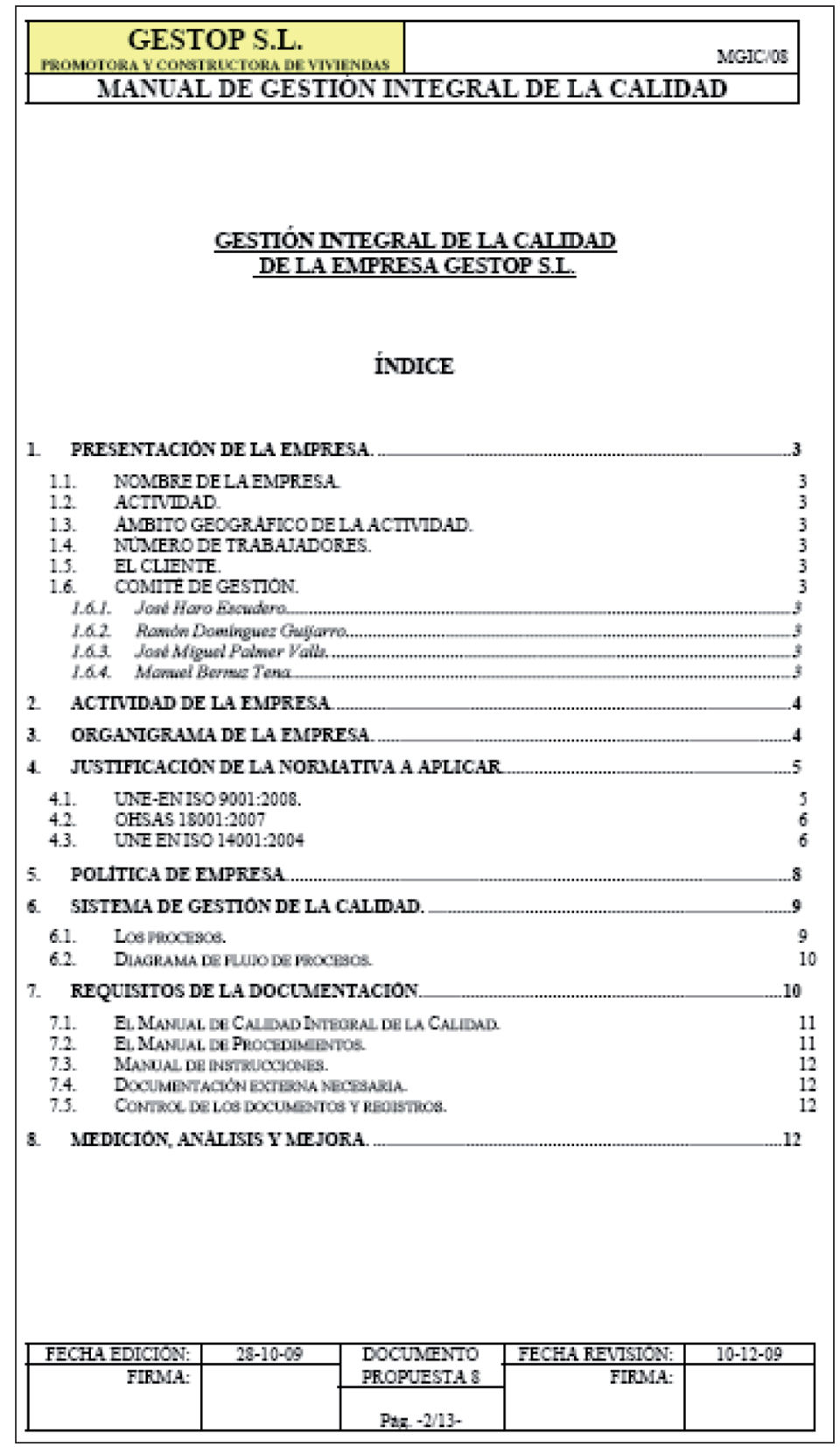

Figura 5: Índice del manual de gestión integral según procesos

b) Forma y contenido de un procedimiento $(\mathrm{P})$.

Los procedimientos son los documentos que definen cómo se debe realizar una actividad o serie de actividades en una empresa concreta. Según la norma ISO 9000:2005, un procedimiento es la forma especificada para llevar a cabo una actividad o un proceso. Este puede estar documentado o no. Según la Iso 9001:2008, como mínimo los procedimientos que se deben documentar y establecer para un SG Son: 
- Control de la documentación.

- Control de los registros.

- Auditorías.

- No conformidades.

- Acciones correctivas.

- Acciones preventivas.

En el caso de estar documentado, se recomienda el siguiente contenido, el cual debe ser desarrollado:

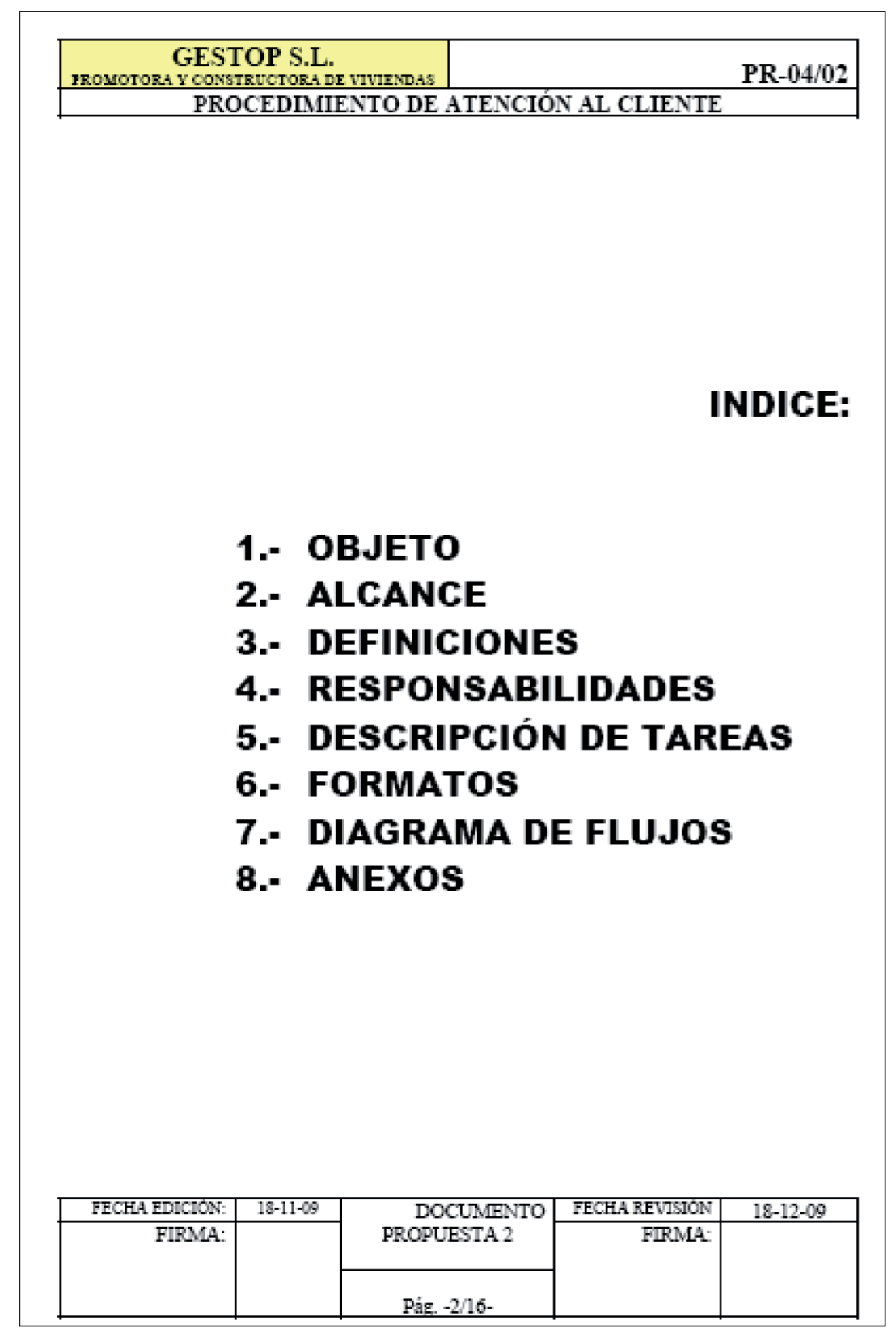

Figura 6: Índice para un procedimiento

Existen otros modelos de procedimientos mucho más esquemáticos, los cuales se basan en un desarrollo a partir del diagrama de flujo de todas las actividades o tareas a desarrollar. 


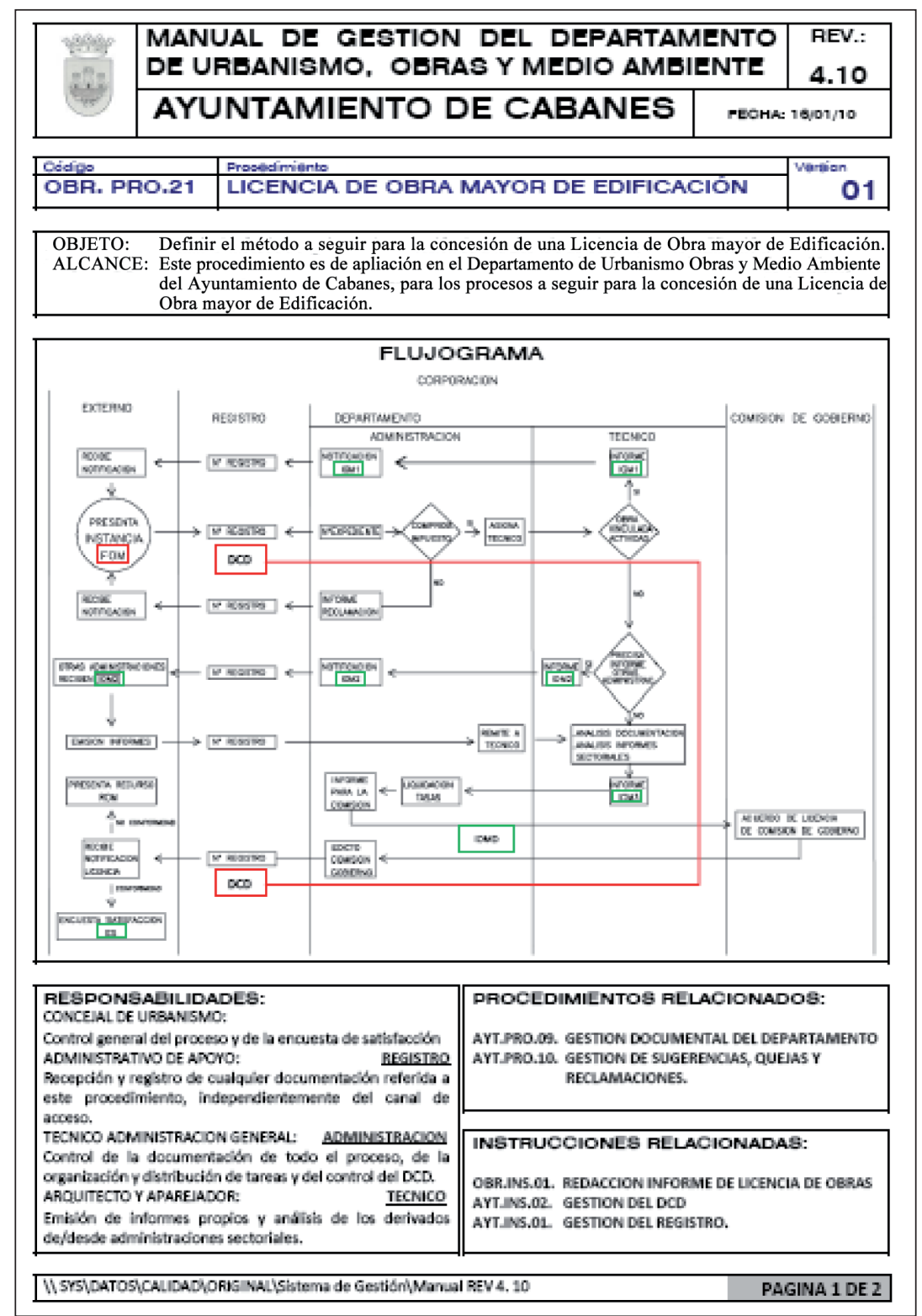

Figura 7: Contenido de un procedimiento basado en su diagrama de flujos

c) Forma y contenido de una instrucción (I).

Aunque la norma Iso 9000 no define el concepto de instrucción, sí que relaciona los documentos que proporcionan información sobre cómo efectuar las actividades y los procesos de manera coherente con los procedimientos documentados, instrucciones de trabajo y planos; por tanto, para nuestro caso particular, una instrucción es un documento con un índice (contenido) igual a un procedimiento, pero este describirá tareas muy concretas o posiblemente tan solo una tarea, debido a su complejidad. Las instrucciones complementan o desarrollan los procedimientos. 


\section{IITULO: PROCESO DE EJECUCIÓN: CUBIERTA.}

\section{DETALLE}

1. REALIZA: Este proceso es realizado por el subcourratista de ejecución de Promocasa Algemesi SL. ALBANILERLA.

2. RESPONSABLES: Responsable de Ejecución de Obra de Promocasa Algemesi S.L. Dirige el proceso el Arquitecto Técrico de Promocasa Algemesi S.L.

3. DOCUMENTOS APLICABLES: Planos de cubierta. Observar planos de reforma, para comprobar posibles modificaciones introducidas por el cliente.

4. PROCESO: La cubierta puede ser de dos tipos:

- cUbierta plana: Azotea transitable o No transitable.

1. Replanteo de pendientes $y$ bajantes. Responsables el Aparejador (Dirección Técnica) y Responsable de Obra de Promocasa Algemesi SL.

$2^{\circ}$. Colocación de cazoletas sifónicas.

$3^{\circ}$. Proyección de poliuretano sobre el forjado, sellando las cazoletas de las bajantes de pluviales.

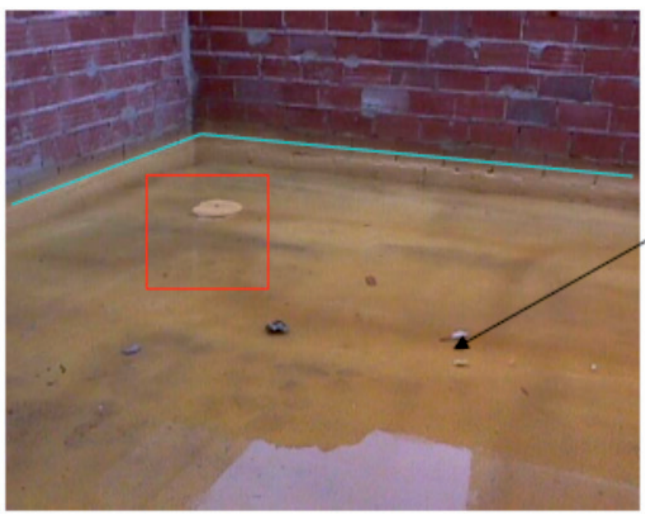

Comentario 1 :

PROYECCIÓN DE

POLIURETANO Y AT

BSTAR.

PROYRCTADA

TAMBIENLA

CAZOLETA, LAS

LLUVIAS NOS

STRVIADE

SRAN PRURBA

GRAN PRUEBA DE

ANTES DE REALIZAR

LA CUBIERTA.

MPROBANO

QUE NO HAY

AGUA, A NO SER

QUE REBASELA

PROYECCIONDE

POLIURETANO.

\begin{tabular}{|c|c|}
\hline PREPARA & REVISA Y APRUEBA \\
\hline DEPARTAMENTO: CONSTRU & DEPARTAMENTO: GERENCIA \\
\hline NOMBRE: Asunción Martinez & NOMBRE: J. Girbés Pérez \\
\hline CARGO: Directora de Calidad & CARGO: Gerente \\
\hline FIRMA: & FIRMA: \\
\hline FECHA: & FECHA: \\
\hline
\end{tabular}

Figura 8: Instrucción de trabajo

d) Forma y contenido de los formatos (F)

Los formatos, fichas, formularios, listas de chequeo son plantillas de documentos que se utilizan para demostrar la aplicación de un procedimiento. Un formato cumplimentado para una obra concreta será un registro o evidencia. 


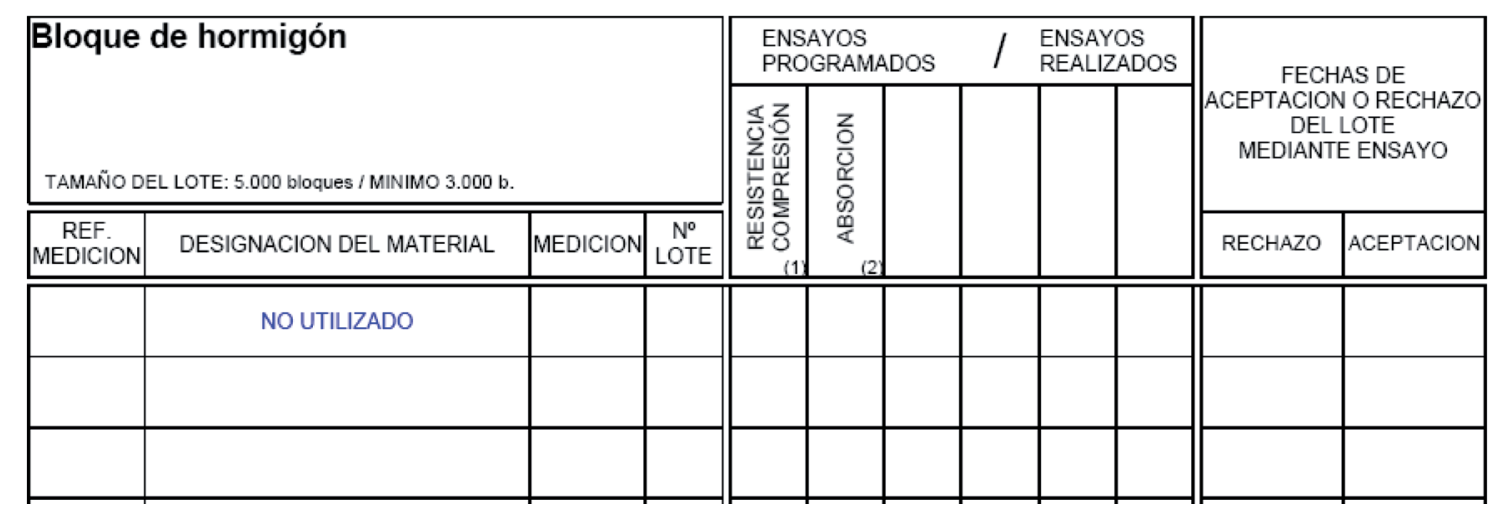

Figura 9: Impreso 4 de la LC91 para el control de los bloques de hormigón

\subsection{Herramientas para la gestión documental}

En el mercado existen varias herramientas informáticas que ayudan a gestionar los documentos de una empresa, muchas de ellas no son específicos para la implantación de sistemas de gestión para normativas [a]. Tan solo Q-doc está diseñado para la gestión de normativas (ISO, QS 9000, vDA 6.1, ISOTS 16949, etc.) de calidad, medio ambiente y prevención de riesgos laborales, sistematizando los flujos de información (aprobación, revisión...) y controlando su distribución. Aun así, si la empresa no desea invertir en herramientas específicas para este fin, el uso de programas estándar y su distribución por medio de la intranet de la empresa, en muchos casos, es más que suficiente.

\section{Referencias}

[1] UNE EN-ISO 9001: 2008. Requisitos para la gestión de la calidad.

[2] UNE EN-ISO 9004:2009. Sistema para la mejora del desarrollo.

[3] UNE 66908: 1998. Guía para la redacción de un manual de la calidad.

[4] Cómo hacer un manual de calidad según la nueva iso 9001:2000. 2008. Fermín Gómez Fraile, Miguel Tejero Monzón, José E. Vilar Barrio. FC Editorial.

[5] Implementing KM Small and Medium Sized Enterprises (SMES) (CWA 14924-3) European Guide to Good Practice in Knowledge Management. European Committee for Standardization, April 2004.

[7] Arquitectura técnica y norma iso 9001. Guía para la implantación de un sistema de calidad. Antonio Garrido Hernández. 1997. 
[8]Cómo hacer el Manual de Calidad según la nueva Iso 9001:2000. Fermín Gómez Fraile, Miguel Tejero Monzón, José F. Vilar Barrio. 2008.

\section{Webs}

[a] OPENPYME. Catálogo para un DMS (Document Management System) http://openpy me.osl.ull.es/DMS/applications

[b] ABAST grup http://qdoc.abast.es/ 